\title{
A diagnostic study of future evaporation changes projected in CMIP5 climate models
}

\author{
A. Laîné $\cdot$ H. Nakamura $\cdot$ K. Nishii • \\ T. Miyasaka
}

Received: 16 January 2013/Accepted: 10 February 2014/Published online: 28 February 2014

(C) The Author(s) 2014. This article is published with open access at Springerlink.com

\begin{abstract}
It has been pointed out that climatologicalmean precipitation-evaporation difference $(P-E)$ should increase under global warming mainly through the increasing saturation level of moisture. This study focuses on evaporation changes under global warming and their dependency on the direct warming effect, on the basis of future projections from the Coupled Model Intercomparison Project Phase 5 (CMIP5). Over most of the tropical, subtropical and midlatitude regions, the direct contribution from surface temperature increase is found to dominate the projected increase in evaporation. This contribution is nevertheless offset partially, especially over the oceans, by contributions from weakening surface winds and increasing near-surface relative humidity. Greater warming of surface air than of the sea surface also acts to reduce surface evaporation, by reducing both the exchange coefficient and humidity contrast at the surface. Though generally of secondary importance, this contribution is the dominant factor over the subpolar oceans. Over the polar oceans, the effect of sea-ice retreat dominantly contributes to the evaporation increase in winter, whereas the reduced exchange coefficient and surface humidity contrast coupled with the sea-ice retreat account for most of the response during summertime. Over the continents, changes in the surface exchange coefficient, reflecting changes in soil moisture and vegetation among other factors, are important
\end{abstract}

A. Laîné $(\bowtie) \cdot$ H. Nakamura · K. Nishii · T. Miyasaka RCAST, The University of Tokyo, Tokyo, Japan

e-mail: laine@aori.u-tokyo.ac.jp

Present Address:

A. Laîné

Atmosphere-Ocean Research Institute, University of Tokyo,

Kashiwa, Japan to modulate the direct effects of the warming and the generally reduced surface air relative humidity.

Keywords Climate change - Climate modeling . Hydrological cycle · Evaporation · CMIP5 · RCP45

\section{Introduction}

As the global climate is warming due to increasing concentration of greenhouse gases (GHGs) in the atmosphere, an expected consequence is an overall intensification of the global hydrological cycle (Huntington 2006; Oki and Kanae 2006), manifested specifically as an enhancement of atmospheric moisture transport, i.e., $P-E$, with $P$ and $E$ representing the climatological-mean precipitation and evaporation rates at a given location. The enhanced moisture transport has been considered mostly as a direct consequence of the increased saturation level according to the Clausius-Clapeyron relationship (Seager et al. 2010). Held and Soden (2006) have shown how this effect is relevant for describing the first-order response of the hydrological cycle simulated under the global warming condition in the models from the fourth Assessment Report of the Intergovernmental Panel on Climate Change (IPCC-AR4).

Another important parameter for the hydrological cycle is evapotranspiration, through which moisture is supplied to the atmosphere. Many studies have been dealing with the complex processes of evapotranspiration on land and its possible changes (e.g. Seneviratne et al. 2010; Liu et al. 2012; Mueller et al. 2011; Jung et al. 2010; Koster et al. 2004). The complexity of measuring, analyzing and modeling evapotranspiration results from great heterogeneity of land surfaces and a large set of parameters to consider, 
including soil properties, characteristics of vegetation and availability of moisture.

In this study, we limit our attention to simple and direct physically-based questions concerning evapotranspiration changes projected in global climate models under the increased GHGs. We hereafter use the general term "evaporation" to refer to the total water flux from the surface to the atmosphere, including sublimation, evaporation of water intercepted by the canopy and transpiration. The specific questions addressed in this paper are:

- What is the relative importance of evaporation changes to precipitation changes locally, compared to the contribution from atmospheric moisture transport (related to $P-E$; Sect. 3)?

- What are the changes in moisture recycling and what are the relative roles of evaporation and precipitation changes (Sect. 4)?

- Which is more important in local evaporation change: a surface wind speed change, a change in air-surface difference in specific humidity or surface property changes, like a sea-ice cover change or a change in the surface exchange coefficient (Sect. 5)?

- What are the relative contributions to surface humidity contrast changes of a direct change in temperature at both the surface and air above (with the same magnitude), of a change in the surface thermal contrast and of surface air relative humidity changes (Sect. 6)?

These specific questions have motivated us to perform detailed analyses of outputs from CMIP5 (Coupled Model Intercomparison Project Phase 5) global climate models used for the IPCC-AR5, as presented below. In this paper, we focus on two seasons: December-January-February (DJF) and June-July-August (JJA). Although the methodology used in Sects. 5 and 6 is more suitable for oceanic surfaces, it has also been applied to land surfaces, as we believe it also gives useful insights to total evapotranspiration changes.

\section{Data and significance tests}

We use output data from fully coupled global ocean-atmosphere models from the CMIP5 database to perform our analyses. We focus on the last twenty years of the twentieth century (1980-1999) for simulations under the historical scenario and the corresponding period (2080-2099) for the twenty first century of simulations under the RCP45 scenario (Taylor et al. 2012). All the output variables have been interpolated linearly onto a $2.5^{\circ} \times 2.5^{\circ}$ latitude-longitude grid before being combined into multi-model ensemble (MME) means, except for surface soil moisture (mrsos) data for which a $0.5^{\circ} \times 0.5^{\circ}$ grid has been used to prevent loss of regional information on narrow land masses, like in Central
America. This latter interpolation can lead to discrepancies locally given the heterogeneity of land and coastal areas (soil type, vegetation, topography, etc.), but is sufficient in our case given the general rather than local purpose of this study.

25 models have been used to perform the MME mean when using monthly-mean data, except for (mrsos) and snow area fraction (snc) for which only 23 and 13 models, respectively, out of the 25 models were available (cf. Table 1 for model names). For our analysis discussed in Sect. 5, daily data are used for validating the method. In this purpose, only 6 models were available.

For each of our analyses, a test of statistical significance, based on a Chi square test with one degree of freedom, has been performed locally, to identify geographical regions where the sign of the MME mean change is robust among the different models at the $95 \%$ confidence level (dotted regions in the different figures).

In order to evaluate the global contribution of a particular contributor $A$ to the total change in a global field $B$, we have defined the projection coefficient of the spatial pattern of the former onto the latter $C_{A, B}$ :

$C_{A, B}=\frac{1}{n \times m} \frac{\sum_{i j} A_{i j} \times B_{i j}}{\sum_{i j} B_{i j} \times B_{i j}}$,

where $n$ and $m$ represent the total numbers of grid cells in latitude and longitude, while $i$ and $j$ indicate the corresponding indices, respectively. Here, $A$ and $B$ are properly area-weighted. We regard it as a convenient measure of global contributions, because their $C$ values sum up to unity if they represent all the terms of an exact decomposition. It is also because it is insensitive to local $B$ values that are close to zero, as is the case for simple spatial averages of local relative contributions.

In our analysis below, any term in the form of $a \times \Delta b$, where $\Delta$ signifies the projected change in a given variable, have been calculated in practice as

$\frac{1}{3} \sum_{\text {month }} \frac{1}{M} \sum_{\bmod }\left[\bar{a}_{20}^{\text {month,mod }} \times\left(\bar{b}_{21}^{\text {month,mod }}-\bar{b}_{20}^{\text {month,mod }}\right)\right]$,

where overbars indicate the seasonal mean of a variable for a given month, the superscript month refers to one of the 3 months of the season considered (DJF or JJA), the superscript mod specifies one of the $M$ models and the subscripts 20 and 21 designate the twentieth and twenty first century experiments, respectively. In linearizing the future projection in the climatological mean state, we regard the twentieth century climate as the reference state.

\section{Relative role of evaporation to precipitation changes}

When averaged in time and neglecting time changes in moisture content of the air column, precipitation rate $P$ can 
Table 1 Lists of the global climate models used for calculating the multi-model ensemble means depending on the data considered

\begin{tabular}{|c|c|c|c|c|}
\hline & $\begin{array}{l}\text { Monthly-mean data, } \\
\text { except mrsos and snc }\end{array}$ & $\begin{array}{l}\text { Monthly-mean surface } \\
\text { soil moisture (mrsos) }\end{array}$ & $\begin{array}{l}\text { Monthly-mean snow } \\
\text { area cover (snc) }\end{array}$ & $\begin{array}{l}\text { Daily-mean } \\
\text { data analysis }\end{array}$ \\
\hline ACCESS1-0 & $X$ & $X$ & & \\
\hline ACCESS1-3 & $\mathrm{X}$ & $X$ & & \\
\hline bcc-csm1-1 & $X$ & $X$ & $X$ & $X$ \\
\hline bcc-csm1-1-m & $\mathrm{X}$ & $X$ & $X$ & \\
\hline CanESM2 & $\mathrm{X}$ & $X$ & & $X$ \\
\hline CNRM-CM5 & $\mathrm{X}$ & $X$ & $X$ & \\
\hline CSIRO-Mk3-6-0 & $\mathrm{X}$ & $\mathrm{X}$ & $\mathrm{X}$ & \\
\hline GFDL-CM3 & $X$ & $X$ & & \\
\hline GFDL-ESM2G & $\mathrm{X}$ & $\mathrm{X}$ & & \\
\hline GFDL-ESM2 M & $X$ & $X$ & & \\
\hline GISS-E2-H & $\mathrm{X}$ & & $X$ & \\
\hline GISS-E2-H-CC & $X$ & $X$ & $\mathrm{X}$ & \\
\hline GISS-E2-R & $X$ & $X$ & $X$ & \\
\hline GISS-E2-R-CC & $X$ & $X$ & $X$ & \\
\hline HadGEM2-AO & $X$ & & & \\
\hline HadGEM2-CC & $X$ & $X$ & & \\
\hline HadGEM2-ES & $\mathrm{X}$ & $X$ & & \\
\hline inmem4 & $X$ & $X$ & $X$ & \\
\hline IPSL-CM5A-LR & $X$ & $X$ & & \\
\hline IPSL-CM5A-MR & $\mathrm{X}$ & $X$ & & \\
\hline IPSL-CM5B-LR & $X$ & $X$ & & \\
\hline MIROC5 & $\mathrm{X}$ & $X$ & $X$ & $\mathrm{X}$ \\
\hline MIROC-ESM & $X$ & $X$ & $\mathrm{X}$ & $\mathrm{X}$ \\
\hline MIROC-ESM-CHEM & $X$ & $X$ & $X$ & $X$ \\
\hline MRI-CGCM3 & $\mathrm{X}$ & $X$ & $X$ & $X$ \\
\hline
\end{tabular}

be considered as a moisture flux out of an air column, which should be balanced by evaporation rate $E$ from the surface and the vertically-integrated horizontal divergence or convergence of atmospheric moisture flux, which therefore corresponds to $P-E$ (e.g., Peixoto and Oort 1992).

Figure 1 shows the MME-mean changes in precipitation, evaporation and $P-E$ for DJF (left panels) and JJA (right panels), based on the 25 climate models listed in Table 1. As evident in Fig. 1a, d, global warming leads to an increase in climatological-mean precipitation mostly in the equatorial regions and in the mid- to high-latitudes, while a general reduction is usually projected in the subtropics. The results are in agreement with many of the previous studies, including those in the IPCC-AR4 (chapter 10 of Solomon et al. 2007), Held and Soden (2006) and Seager et al. (2010). These large-scale features of precipitation changes are overall robust among the models according to the Chi square test mentioned in Sect. 2. Note that the precipitation changes tend to be greater in winter than in summer, especially in the mid- to high-latitudes, while zonal asymmetries of precipitation changes in the subtropics seem greater in the summer hemisphere (Fig. 1a, d).
The contributions from the moisture flux to the MMEmean precipitation changes are shown in Fig. 1b, e for DJF and JJA, respectively. In each of these figures (and others shown afterwards), geographical domains are hatched where the particular quantity plotted is the dominant contributor to the total change considered, which is precipitation in this case. The figures indicate that the changes in moisture flux are the main contributor to the precipitation changes in many regions, shaping the global patterns of precipitation changes described above. In fact, the changes are mostly manifested as an enhancement of the $P-E$ pattern in the present-day climate, with increased convergence of the moisture fluxes into wet regions such as the Maritime Continent, Inter-Tropical Convergence Zone (ITCZ) and midlatitude oceanic storm tracks, and enhanced divergence of the fluxes out of the subtropical oceans where excessive surface evaporation occurs and surface winds are diverging (Held and Soden 2006; Seager et al. 2010). This $P-E$ amplification can be attributed primarily to the direct effect of air temperature increase on the saturation level and hence the total humidity transported. This effect also contributes substantially to enhanced zonal 


\section{$D J F$}

(a)

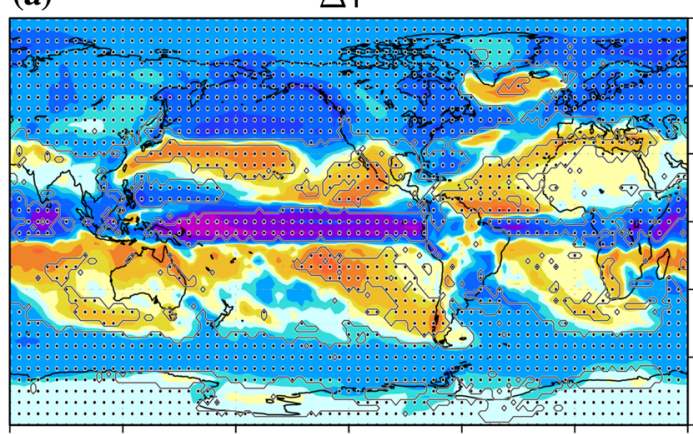

(b)

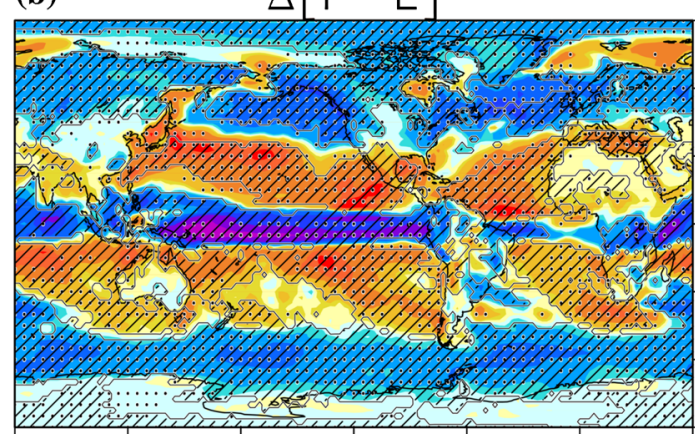

(c)

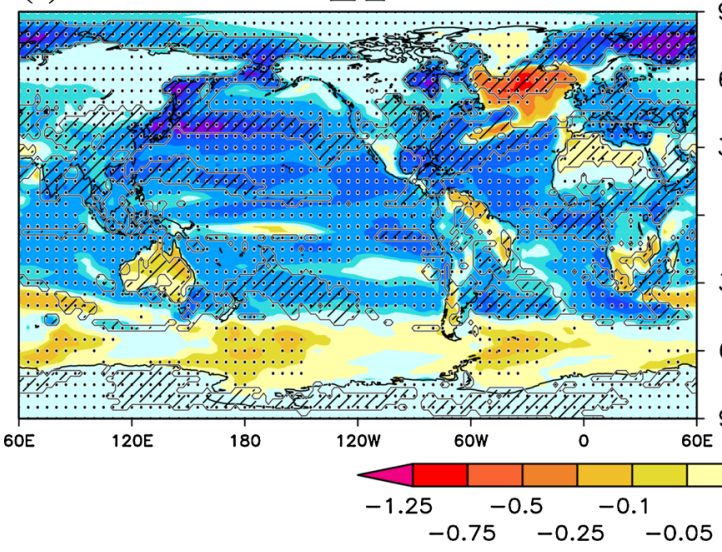

Fig. 1 25-model ensemble mean (cf. Table 1) changes in precipitation ( $P$; upper panels), $P-E$ (middle panels) and evaporation $(E$; lower panels) for the DJF (left panels) and JJA (right panels) seasons. Regions are dotted in which the sign of the changes is robust among

asymmetries in the projected future precipitation in the summertime subtropics.

The corresponding contributions from surface evaporation are shown in Fig. 1c for DJF and in Fig. 1f for JJA. For both seasons, evaporation generally increases, except over (semi-) arid continental regions in the subtropics, over the subpolar North Atlantic, including the Gulf Stream Extension and the Labrador Sea, along the Agulhas Return Current over the midlatitude South Indian Ocean, over the subpolar Southern Oceans and the Arctic Ocean in

\section{$J J A$}
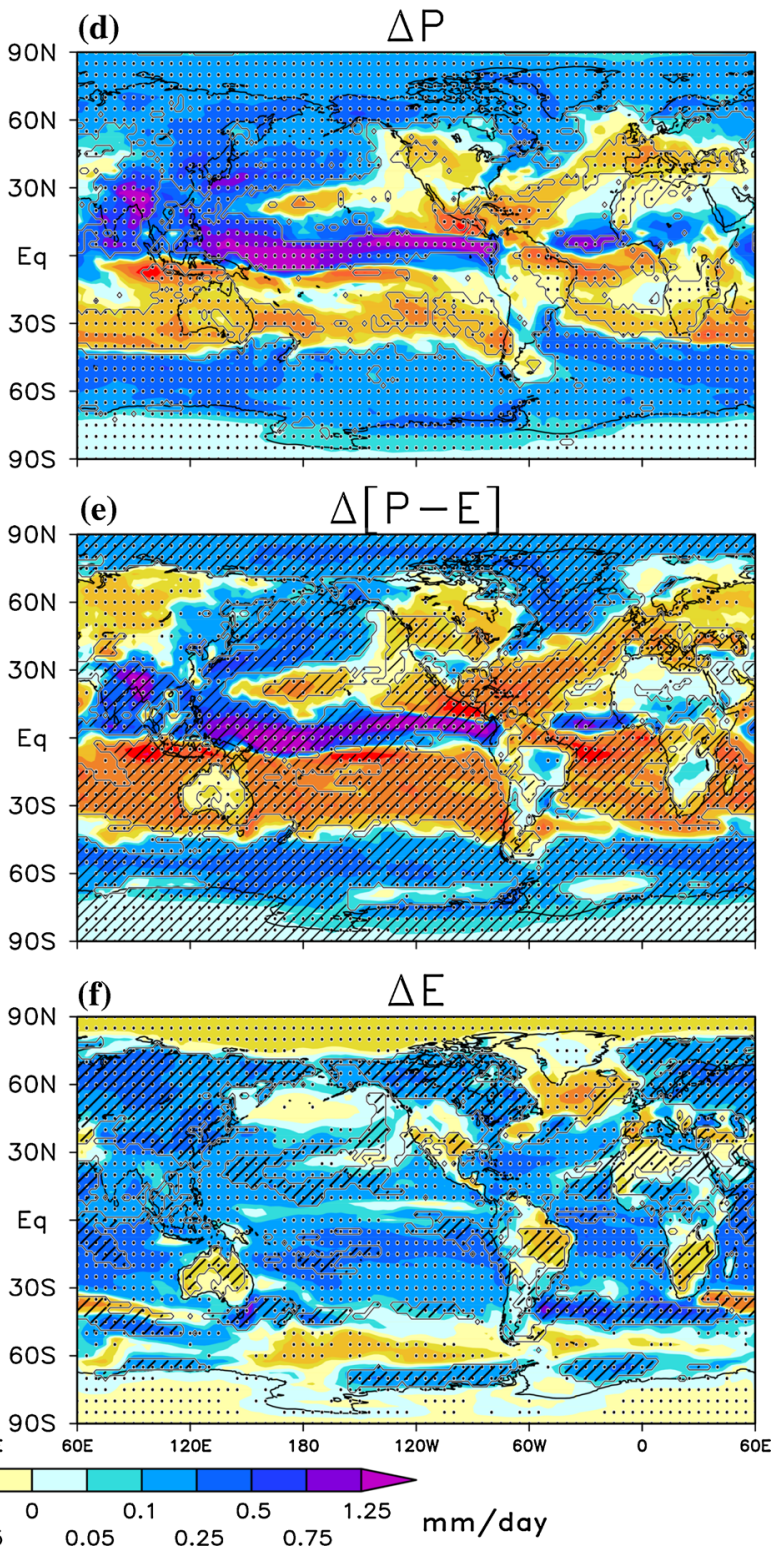

the models (cf. Sect. 2). In the middle and lower panels, regions are hatched in which the particular contribution dominates the precipitation changes indicated in the upper panels

summer. The evaporation increase over the ocean tends to be larger during winter months, especially over midlatitude western boundary current (WBC) regions and over polar oceans where sea-ice cover greatly reduces. By contrast, over the continents, the changes tend to be larger in summer months, especially over the boreal subpolar continents. Though of secondary importance in most of the regions, the influence of surface evaporation on the mean precipitation changes is of primary importance in winter over the polar oceans and along midlatitude WBCs, and over eastern parts 
Table 2 Projection coefficients, expressed as percentages, of evaporation changes to precipitation changes

\begin{tabular}{llllllll}
\hline & Global (\%) & Global continents (\%) & Global oceans $(\%)$ & NH25 continents $(\%)$ & NH25 oceans (\%) & SH25 continents (\%) & SH25 oceans (\%) \\
\hline DJF & 16 & 32 & 13 & 34 & 47 & 47 & -4 \\
JJA & 11 & 35 & 8 & 38 & 17 & 31 & 20 \\
\hline
\end{tabular}

$\mathrm{NH} 25$ and SH25 refer to the Northern and Southern Hemispheres, respectively, poleward of $25^{\circ}$. Note that the land surface area south of $25^{\circ} \mathrm{S}$ is much smaller than north of $25^{\circ} \mathrm{N}$, leading to more local, less general numbers

of the midlatitude continents, especially in winter and over subpolar continents, especially in summer.

Table 2 shows the projection coefficients (Sect. 2) of evaporation changes onto the precipitation changes for both seasons, evaluated globally, separately for the oceans and continents and for the extratropics in the Northern and Southern Hemispheres (poleward of $25^{\circ}$ ). The global contribution from the evaporation changes to the local precipitation changes is only 16 and $11 \%$ for DJF and JJA, respectively. From the global viewpoint, the contribution is substantially larger over the continents than over the oceans (32-35\% compared to 8-13\%). Over the extratropical oceans, it is greater in winter in both hemispheres, while there is a tendency for the contribution over the extratropical continents to be greater in summer months.

\section{Changes in the role of local evaporation to precipitation}

In what follows, part of precipitation that directly originates from local evaporation is referred to as "local evaporation contribution to precipitation" hereafter. It includes, by definition, a certain level of arbitrariness, as it depends on the size of the domain for which it is evaluated; the greater the domain the greater the probability is for local moisture recycling with evaporation. More precise evaluation of this "evaporation contribution" requires tracking of individual water particles after evaporating from the surface until returning to the surface (van der Ent and Savenije 2011). In our case, however, we adopt a crude measure of "local" contribution that is defined as $E / P$ in a climatological sense for a particular grid cell of $2.5^{\circ}$ in latitude and longitude in size. Since $E / P=1-(P-E) / P$, it also represents the part of precipitation that does not originate from moisture transport. The ratio is greater than unity in regions of excessive evaporation over precipitation, i.e., regions of the net moisture export, including large parts of the subtropical oceans, while it is inferior to unity in regions of the net moisture convergence, e.g., in the equatorial regions and mid to high latitudes, especially over the continents (Fig. 2a, e).

The projected local change in evaporation contribution based on our definition may be expressed in the form of its fractional change: $\Delta[E / P] /[E / P]$, which may be decomposed into the corresponding fractional changes in precipitation and evaporation at first order, since $\partial \ln x=\partial x / x$, for any variable $\mathrm{x}>0$ :

$$
\begin{aligned}
\Delta[E / P] /[E / P] & \approx \Delta \ln (E / P) \approx \Delta \ln (E)-\Delta \ln (P) \\
& \approx \Delta E / E-\Delta P / P .
\end{aligned}
$$

This formula indicates that the evaporation contribution to the local moisture recycling will be enhanced if the relative change in evaporation exceeds that in precipitation, and the opposite is the case in the regions of reduced moisture recycling.

As shown in Fig. 2b, f, augmentation of the local moisture recycling is projected over most of the continental regions and over the subtropical and midlatitude oceans, in addition to the wintertime polar oceans. Conversely, the local moisture recycling will be reduced in the equatorial regions, especially over the Pacific and Indian Oceans and over the subpolar gyres, in addition to the summertime polar oceans.

Figure $2 \mathrm{~b}-\mathrm{h}$ indicate that, over the tropical and subtropical oceans, most of the aforementioned fractional relative changes in the local moisture recycling are due primarily to relative changes in precipitation that largely exceed those in evaporation. Conversely, the fractional evaporation changes tend to dominate over the precipitation changes over boreal subpolar/midlatitude continents and the polar oceans. Over the subpolar oceans, both precipitation and evaporation tend to be of comparable importance to the fractional moisture recycling changes.

\section{Relative roles of changes in individual factors in the projected changes in surface evaporation}

Total evaporation rates in the global climate models are usually expressed in the form of bulk formula like (e.g. eq. (6) of Takata et al. 2003):

$E=\sum_{\text {type }}\left[\alpha_{\text {type }} C_{\text {type }} \rho\left|\vec{v}_{s}\right|\left(h_{\text {type }} q_{\text {sat,type }}-q_{\text {air }}\right)\right]$,

or (e.g. Section 3a of Ducoudré et al. 1993):

$E=\sum_{\text {type }}\left(\alpha_{\text {type }} \rho \frac{h_{\text {type }} q_{\text {sat,type }}-q_{\text {air }}}{\sum_{i} \text { type }} R_{i}\right)$, 


\section{$D J F$}

(a)

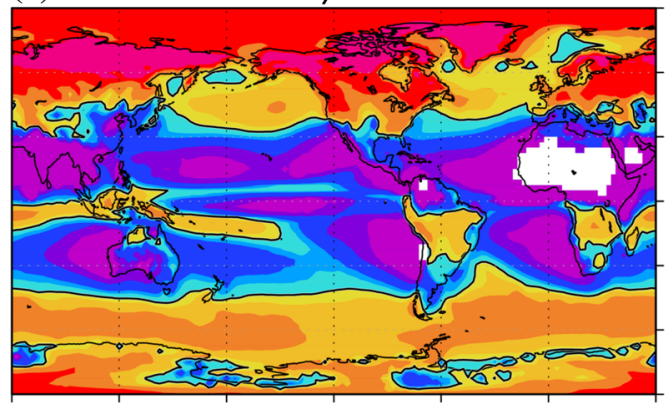

$J J A$

(e)

$E / P$

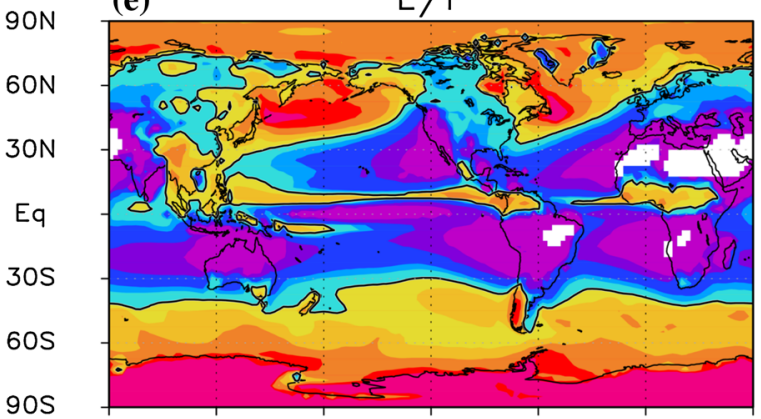

$100 \quad 150 \quad 200 \quad 500 \quad 1000 \quad \%$
$\Delta[E / P] /[E / P]$

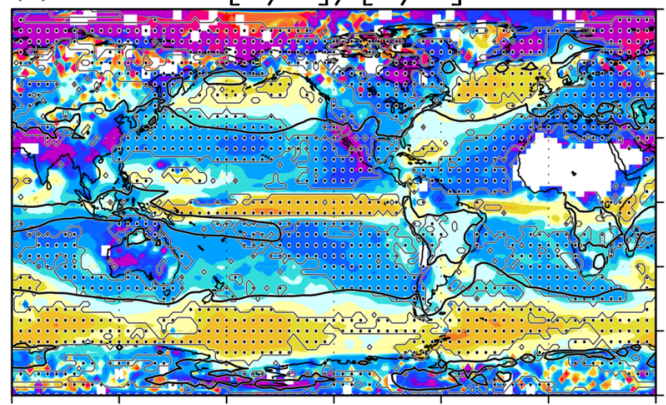

(c)

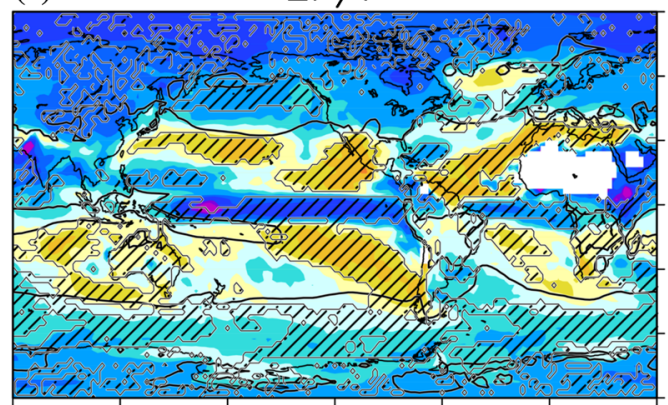

(d)

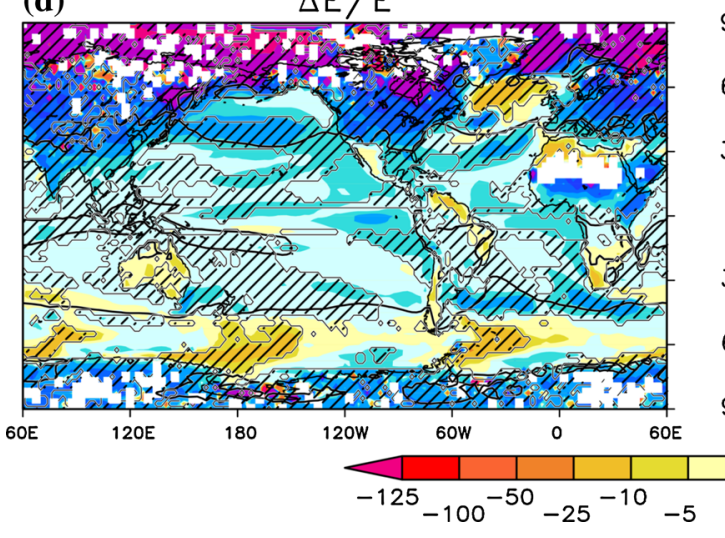

Fig. 2 25-model ensemble mean (cf. Table 1) of "local evaporation contribution to precipitation" $E / P$ for the twentieth century simulations $(\mathbf{a}, \mathbf{e})$ and its projected relative change $(\mathbf{b}, \mathbf{f})$ for the DJF (left panels) and JJA (right panels) seasons, and the corresponding relative changes in precipitation $(\mathbf{c}, \mathbf{g})$ and in evaporation $(\mathbf{d}, \mathbf{h})$. Solid black (f) $\quad \Delta[\mathrm{E} / \mathrm{P}] /[\mathrm{E} / \mathrm{P}]$

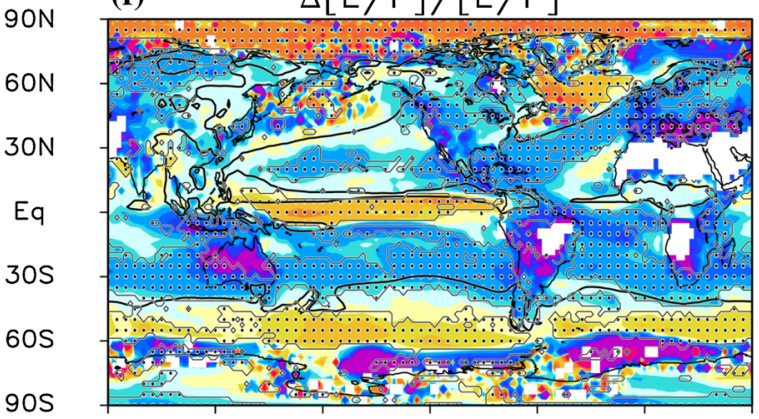
(g)
$\Delta P / P$

$90 \mathrm{~N}$

$60 N$

$30 N$

$\mathrm{Eq}$

305

605

9os

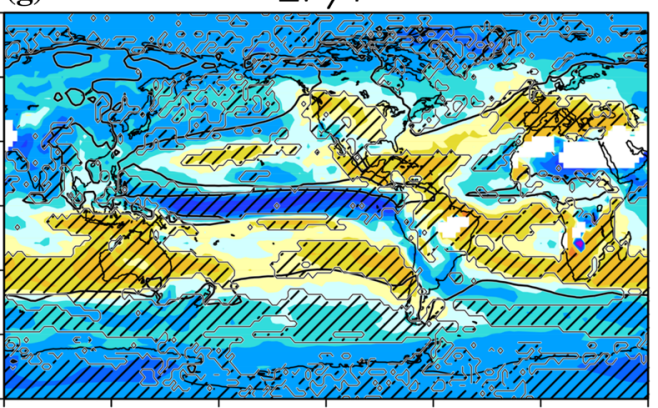
(h)
$\Delta \mathrm{E} / \mathrm{E}$

$90 \mathrm{~N}$

$60 N$

$30 N$

Eq

305

605

905

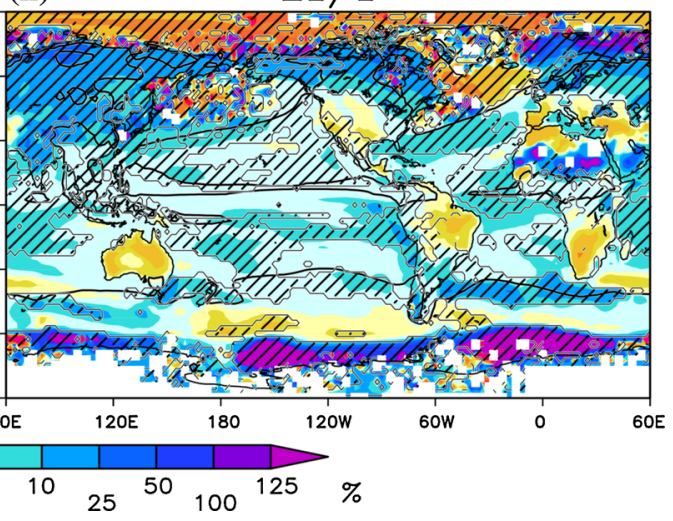

lines in every panel represent $E / P=1$, as shown in (a, e). In panels $\mathbf{b}$ and $\mathbf{f}$, regions are dotted in which the sign of the relative change in $E / P$ is robust among the models (cf. Sect. 2). In $\mathbf{c}, \mathbf{g}$ and $\mathbf{d}, \mathbf{h}$, regions are hatched in which $-\Delta P / P$ and $\Delta E / E$, respectively, dominates the relative changes in $E / P$ 
where type refers to the type of surface (e.g. open water, sea-ice, bare soil covered with snow or not covered with snow, canopy, covered or not with snow or intercepted water), $\alpha_{\mathrm{type}}$ the fraction of the given surface type within the grid cell, $\rho$ surface air density, $\left|\vec{v}_{s}\right|$ surface wind speed, $h_{\text {type }}$ some coefficient representing the relative humidity of the surface type, $q_{\text {sat,type }}$ the saturation value of specific humidity of type, $q_{\text {air }}$ the specific humidity of the air at the surface. In (4), an exchange coefficient $C_{\text {type }}$ defined semi-empirically comprises a constant part and another part that is usually dependent on the Richardson number and other surface parameters (e.g., Miller et al. 1992). In (5), this exchange coefficient is written as an inverse of a sum of resistances $1 /\left(\sum_{i}\right.$ type $\left.R_{i}\right)$. In this latter case, an aerodynamic resistance $R_{a}$ usually includes the effect of surface wind speed and surface drag coefficient $C_{d}$, which tend to favor evaporation: $R_{a}=1 /\left(C_{d}\left|\vec{v}_{s}\right|\right)$. Different resistances can be added depending on the surface type considered (e.g. Ducoudré et al. 1993).

Since an exact decomposition of the evaporation fluxes is not possible given the lack of model outputs available and the various parametrizations used in the different models, we approximate the decomposition of evaporation fluxes for each model in the simple form:

$E=C \rho\left|\vec{v}_{s}\right| \delta q_{s}$,

with $C$ a general exchange coefficient defined locally and $\delta q_{s}=q_{\text {surf }}-q_{\text {air }}$ representing specific humidity difference between the surface $\left(q_{\text {surf }}\right)$ and air just above it $\left(q_{\text {air }}\right)$. We use available data for evaporation, $10-\mathrm{m}$ wind speed, surface air pressure, skin and 2-m air temperatures ( $T_{s}$ and $T_{\text {air }}$ respectively) and 2-m air relative humidity $(r)$ to define or approximate the different terms of (6). Indeed, saturation level of specific humidity can be assessed from temperature and pressure through the Clausius-Clapeyron relationship:

$q_{\mathrm{sat}}(T, p)=\frac{R_{\mathrm{air}} p_{s 0}}{R_{v} p} \exp \left(-\frac{L_{v}}{R_{v} T}+\frac{L_{v}}{R_{v} T_{0}}\right)$,

where $R_{\text {air }}=287 \mathrm{~J} \mathrm{~K}^{-1} \mathrm{~kg}^{-1}$ is the gas constant for dry air, $R_{v}=461 \mathrm{~J} \mathrm{~K}^{-1} \mathrm{~kg}^{-1}$ the gas constant for water vapor, $p_{s 0}=6.11 \mathrm{hPa}$ the reference saturation vapor pressure at $T_{0}=273.15 \mathrm{~K}, L_{v}=2.501 \times 10^{6} \mathrm{~J}_{\mathrm{kg}} \mathrm{kg}^{-1}$ the latent heat of vaporization, $p$ air pressure and $T$ air temperature. We consider that the specific humidity at the surface is at its saturation value $q_{\text {surf }}=q_{\text {sat }}\left(T_{s}, p_{s}\right)$, whereas we use the near-surface relative humidity $r$ to determine the specific humidity at 2-m $q_{\text {air }}=r \times q_{\text {sat }}\left(T_{\text {air }}, p_{s}\right)$.

For sea-ice covered regions, we attempt to isolate explicitly the role of sea-ice cover from other parameters, by assuming that evaporation is negligible over sea ice compared to the open ocean. We can thus generalize (6) into the formula:

$E=\operatorname{sic} C \rho\left|\vec{v}_{s}\right| \delta q_{s}^{*}$,

where (sic) represents the sea-ice concentration within a given grid cell, and

$\delta q_{s}^{*}=\left[q_{\mathrm{sat}}\left(T_{s}^{*}, p_{s}\right)-r \times q_{\mathrm{sat}}\left(T_{\mathrm{air}}, p_{s}\right)\right]$,

where $T_{s}^{*}$ indicates the surface skin temperature except over sea-ice cover regions where it represents sea-surface temperature (SST).

$C \rho$ is then indirectly inferred through:

$C \rho \approx \frac{E}{\operatorname{sic}\left|\vec{v}_{s}\right| \delta q_{s}^{*}}$.

This approximation should be appropriate over the oceans $\left(h_{\text {ocean }}=1\right.$ in (4) and (5), and usually only aerodynamic resistance in models using evaporation schemes like (5)), although the variability with frequencies higher than the original data frequency is neglected. Over the continents, this decomposition should be less accurate than over the oceans since the different surface types and their associated parameterization are approximated into a single Eq. (8). The different temperatures, exchange coefficients or resistances, and water contents of the different surface types are not considered separately but only as a whole, using the surface-skin temperature and considering a flat, saturated surface $(h=1$ in (4) and (5) whatever the surface type). This latter approximation does not mean that surface-skin relative humidity is not considered in the decomposition, since it should be included indirectly in $C \rho$ when calculated through Eq. (10). It rather means that the Eq. (8), that we use a-posteriori for diagnosing the different influences, is not exactly the one used in the models, hence leading to discrepancies in the various terms, especially on land. Keeping this warning in mind, we think it is still informative to consider the results also for the continents as it can give useful, first guess insights of processes at stake.

From (8), evaporation changes can then be decomposed as:

$$
\begin{aligned}
\Delta E= & C \rho\left|\vec{v}_{s}\right| \delta q_{s}^{*} \Delta \operatorname{sic}+\operatorname{sic}\left|\vec{v}_{s}\right| \delta q_{s}^{*} \Delta[C \rho] \\
& +\operatorname{sic} C \rho \delta q_{s}^{*} \Delta\left|\vec{v}_{s}\right|+\operatorname{sic} C \rho\left|\vec{v}_{s}\right| \Delta \delta q_{s}^{*} \\
& +\Delta_{\mathrm{var}} E+\Delta_{\text {inter }} E,
\end{aligned}
$$

where the different terms $C \rho,\left|\vec{v}_{s}\right|, \delta q_{s}^{*}$, sic correspond to climatological monthly means (not represented with overbars for clarity). The first term on the right-hand side (RHS) therefore represents the changes in evaporation related to a change in climatological monthly mean sea-ice cover $\left(\Delta_{\mathrm{sic}} E\right)$, the second term to changes in the climatological monthly mean exchange coefficient at the surface 
$\left(\Delta_{C \rho} E\right)$, which should depend mostly on the Richardson number over the oceans but also on parameters related to different soil and vegetation properties over the continents. The third term is associated with changes in climatological monthly mean surface wind speed $\left(\Delta_{v} E\right)$, the fourth one to changes in climatological monthly mean humidity contrast at the surface $\left(\Delta_{\delta \mathrm{q}} E\right)$. The term $\Delta_{\mathrm{var}} E$ includes the terms related to interannual variability and also submonthly variability if using daily or higher frequency data. Finally $\Delta_{\text {inter }} E$ represents the interaction between the different changes themselves, i.e. the second to fourth order terms.

The use of daily-mean data (or of higher frequency) rather than monthly-mean data should lead to a better approximation for $C \rho$. Nevertheless, we found the difference to be rather small when comparing the reconstruction using daily and monthly data with the 6 models listed in Table 1. Although those two kinds of reconstructions do not yield identical results, the differences are relatively small and do not lead to any qualitative differences in the individual terms in (11) (not shown). Therefore, we used monthly-mean data for presenting our results, turning it to advantage that the number of models available in this case is significantly larger than for daily-mean variables (25 compared to 6 models, cf. Table 1).

Figures 3 and 4 show the results of the decomposition (11) for DJF and JJA, respectively. For both seasons, in most regions, the primary factor responsible for local evaporation changes (Figs. 3a, 4a) is related to changes in the surface humidity contrast (Figs. 3d, 4d), contributing to the general increase in evaporation globally. The humidity difference also contributes to decreasing evaporation over subpolar oceans all year-round. Nevertheless, this factor is not dominant for some specific areas and seasons. Especially, over the polar oceans in the winter hemisphere, the increased evaporation arises mainly from sea-ice retreat (Figs. 3b, 4b). Over continental regions where decreasing evaporation is projected in the models, the factor responsible for this decrease is related to changes in the exchange coefficient factor (Figs. 3c, 4c). This factor also contributes significantly to evaporation enhancement in some specific regions, especially from the Sahel to the Horn of Africa, India, eastern Europe and the northeastern United States during boreal winter (Fig. 3c), and around eastern India and the Tibetan Plateau during boreal summer (Fig. 4c). The reduced evaporation cases are associated with drier soil conditions for both seasons (Figs. 5c, 6c), whereas evaporation increases seem to be associated with wetter condition for JJA but not always for DJF. In this latter situation (evaporation increase whereas drier surface soil moisture), vegetation changes may explain the changes in the exchange coefficient. Zonally-elongated oceanic regions where changes in the exchange rate coefficient contribute to the changes in evaporation (Figs. 3c, 4c) correspond well to the areas of reduced surface instability or increased stability at the surface (Figs. 5d, 6d).

The contribution from the changes in surface wind speed (Figs. 3e, 4e) is overall of secondary importance, though it can be locally dominant in some oceanic regions. Specifically, the increasing evaporation over the tropical South Pacific and the midlatitude Southern Oceans (Figs. 3e, 4e), especially the South Indian Ocean and to the south of Australia, are due primarily to the strengthening of the Trades and westerlies, respectively (Figs. 5a, 6a). Likewise, decreasing evaporation in the eastern subtropical North Pacific is due primarily to the weakening of the Trades. In other tropical and subtropical regions where weakening of surface wind speed (Figs. 5a, 6a) acts to reduce evaporation, this wind speed effect is overwhelmed by the compensating effect of the increasing air-surface humidity difference (Figs. 3d-e, 4d-e). The general reduction in surface wind speed in the Tropics is consistent with a general weakening of tropical overturning circulation projected in the climate models (Figs. 5b, 6b; Vecchi and Soden 2007; DiNezio et al. 2013), whereas poleward shifts of the subtropical high-pressure systems and the midlatitude westerlies act to yield dipolar patterns of surface wind speed changes in the midlatitudes with weakening and strengthening in the subtropics and subpolar regions, respectively (Figs. 5a-b, 6a-b; Lu et al. 2007; Hu et al. 2013; Chang et al. 2012).

The influence of the interannual variability on the seasonal mean, depicted in Figs. $3 \mathrm{~h}$ and $4 \mathrm{~h}$, are relatively small and mostly represent interannual variability of seaice cover and its margins. The second to fourth order changes (Figs. 3g, 4g) are relatively strong but usually of secondary importance. A noticeable exception emerges in the sea-ice covered regions during summer, where this factor becomes dominant to explain the reduction in evaporation for both seasons. It means that some changes become greater than or of the same order of magnitude as the mean field itself, which can be typically the case for sea-ice retreat. In fact, the main interaction leading to this evaporation reduction is between the sea-ice cover retreat and the changes in both exchange coefficient and surface humidity contrast. These regions of summertime sea-ice retreat are associated with a particularly strong increase in air temperature that exceeds the corresponding increase at the surface. Note that this warming difference cannot be seen in Figs. $5 \mathrm{~d}$ and $6 \mathrm{~d}$ where only the difference between $T_{\text {air }}$ and SST is shown over the oceans, rather than that between $T_{\text {air }}$ and skin-surface temperature over sea ice. This thermal contrast change induces a greater reduction in near-surface stratification and thereby in the exchange coefficient. It also reduces the surface humidity contrast as will be explained in the next section. 


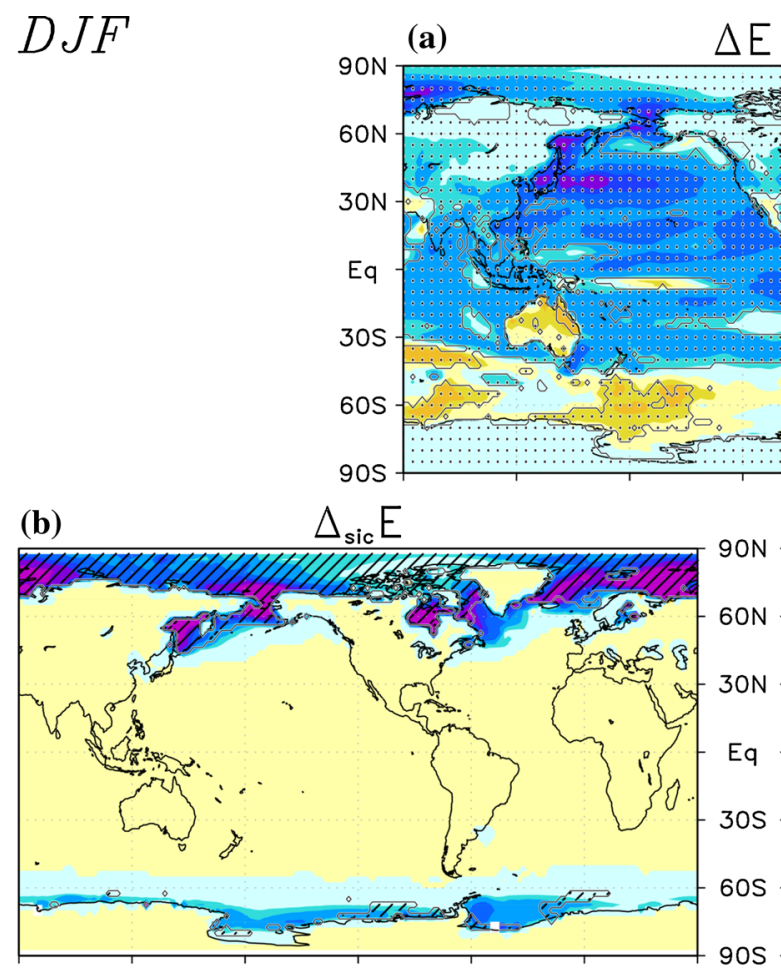

(d) $\quad \Delta_{\delta q} E$
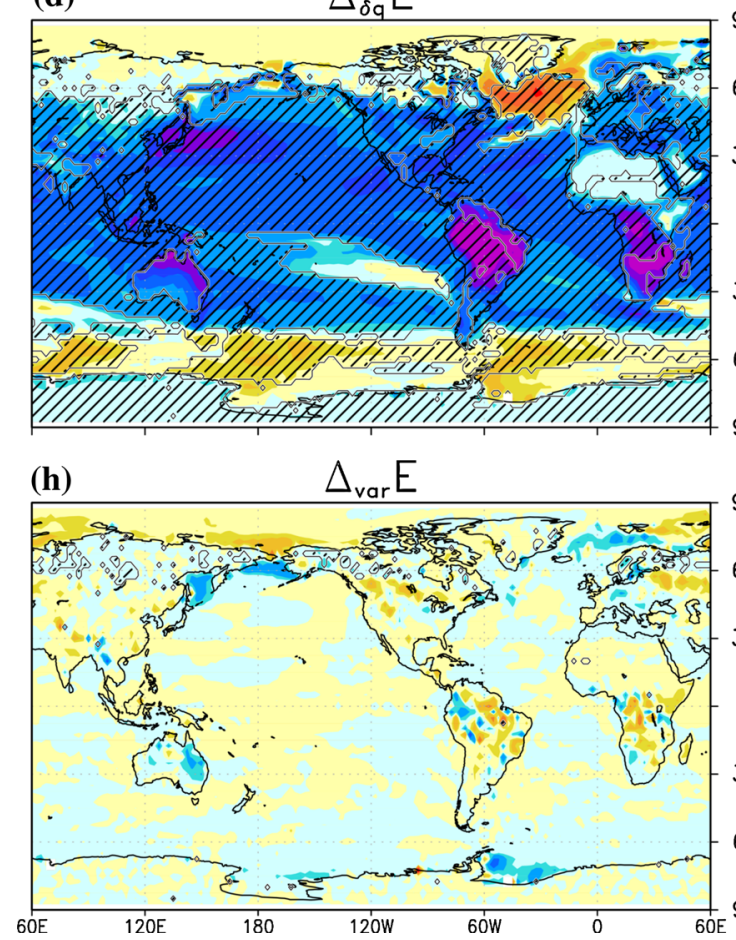

Fig. 3 a 25-model ensemble mean (cf. Table 1) changes in evaporation for the DJF season. Dotted regions in a indicate those in which the sign of evaporation change is robust among models (cf. Sect. 2).

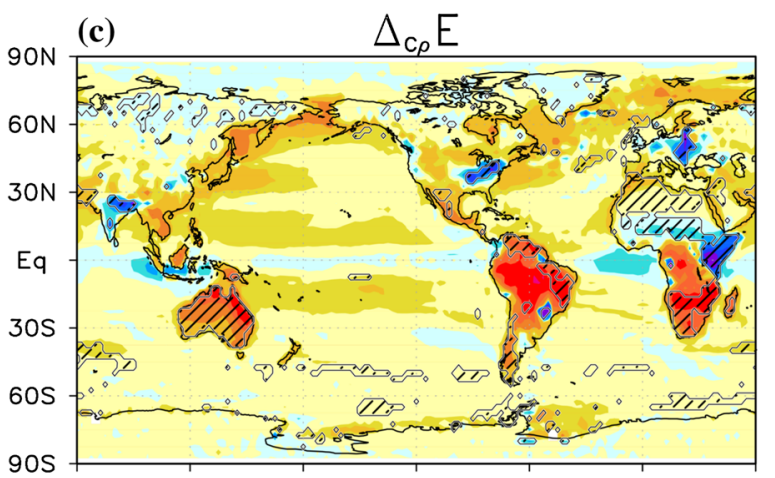

(e) $\quad \Delta_{v} E$
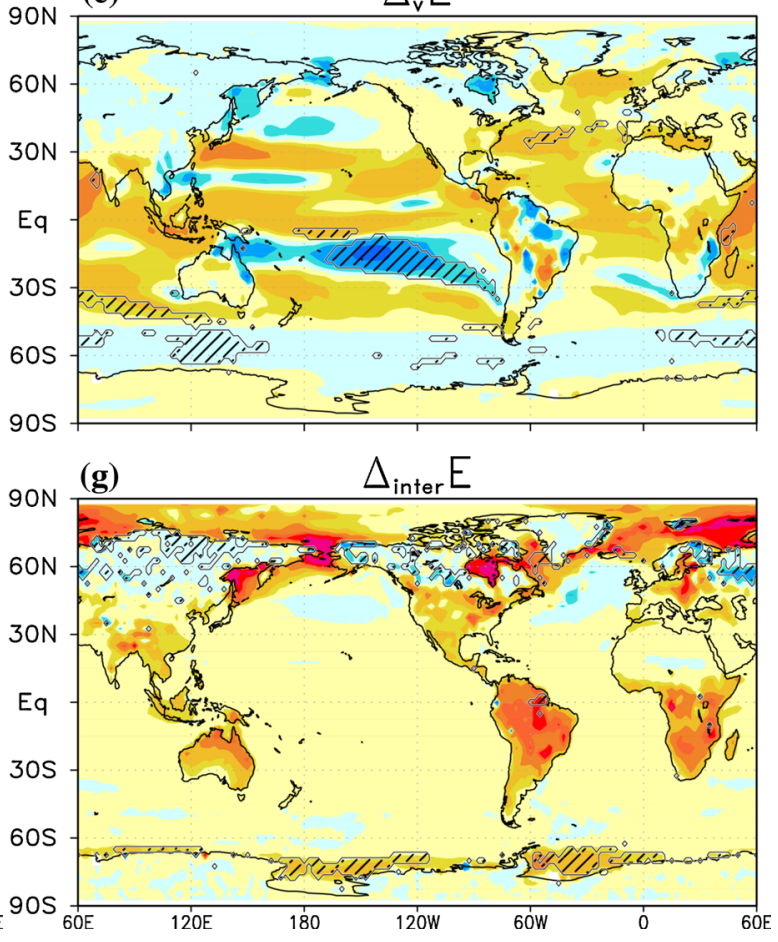

b-g Contributions from individual terms in (11). Hatched regions represent those in which the particular contribution dominates the changes plotted in a 

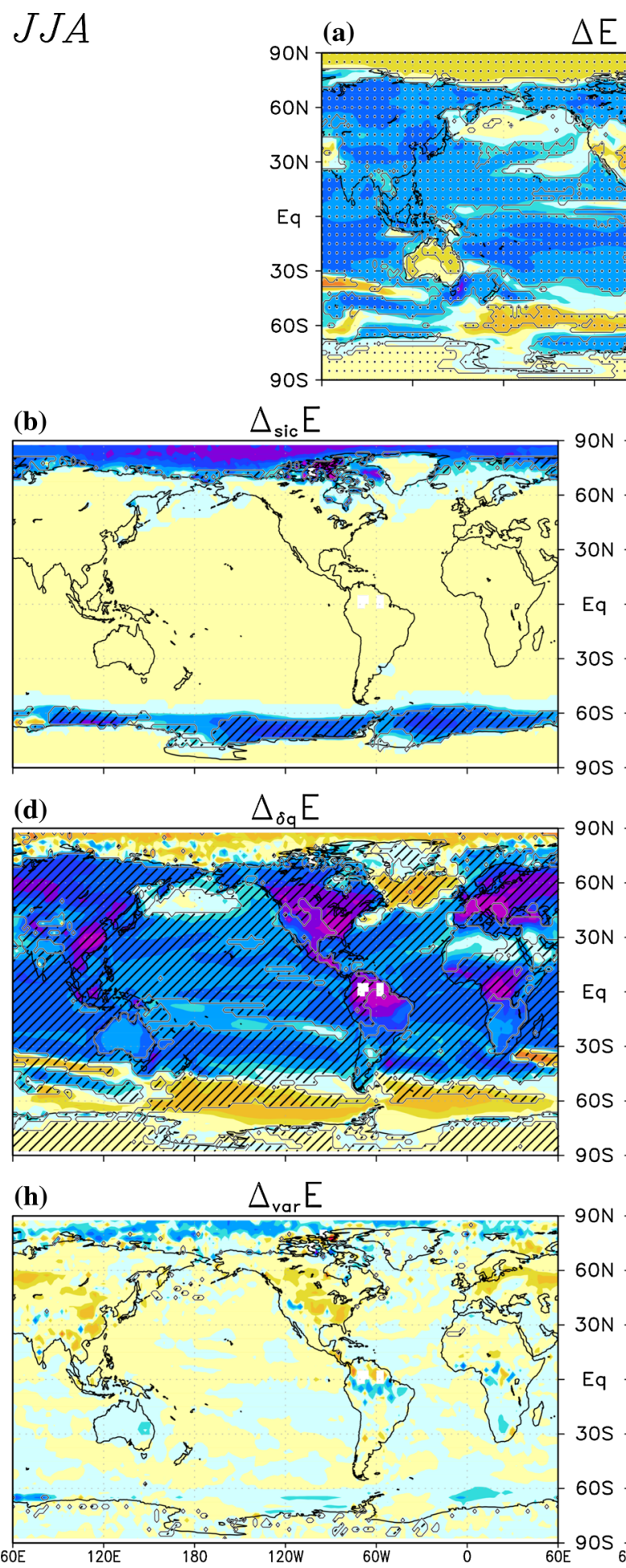

Fig. 4 Same as Fig. 3 but for JJA season

\section{Factors contributing to changes in air-surface humidity differences}

The analyses thus far indicate that the projected evaporation changes are generally contributed to mainly by the
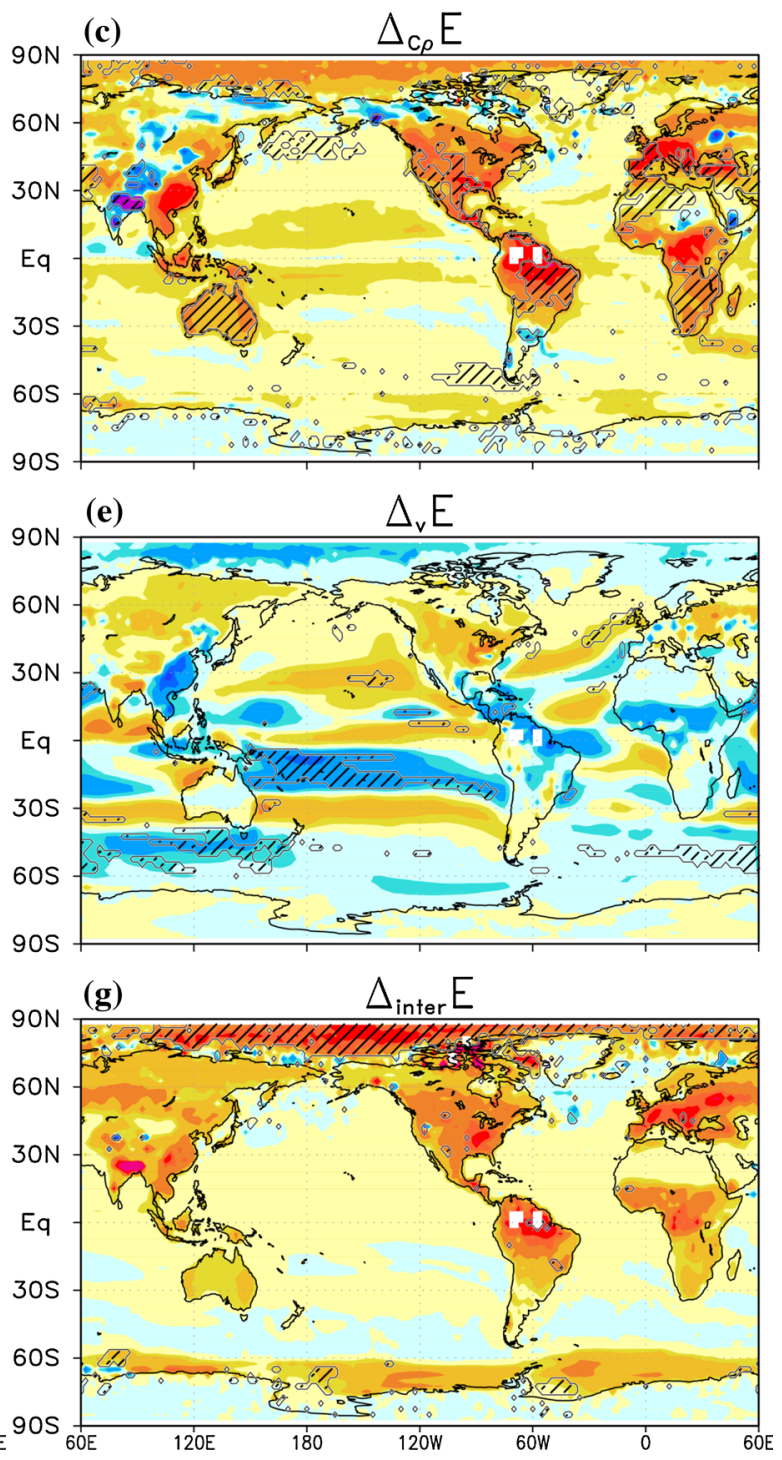

(e) $\quad \Delta_{v} E$

(g) $\quad \Delta_{\text {inter }} E$

changes in near-surface humidity contrast. In the following, we attempt to identify factors that exert substantial influence on them.

As shown in (7), the near-surface humidity contrast can be evaluated with the Clausius-Clapeyron relationship. We 


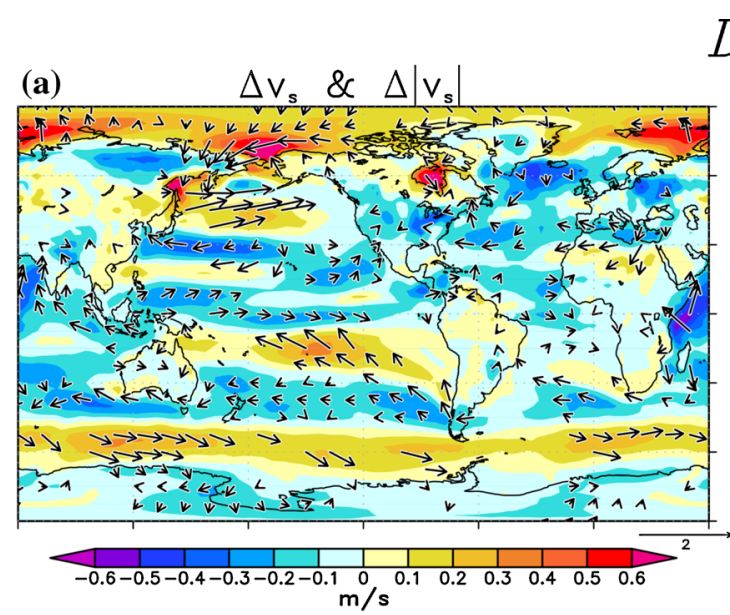

$D J F$

(c)

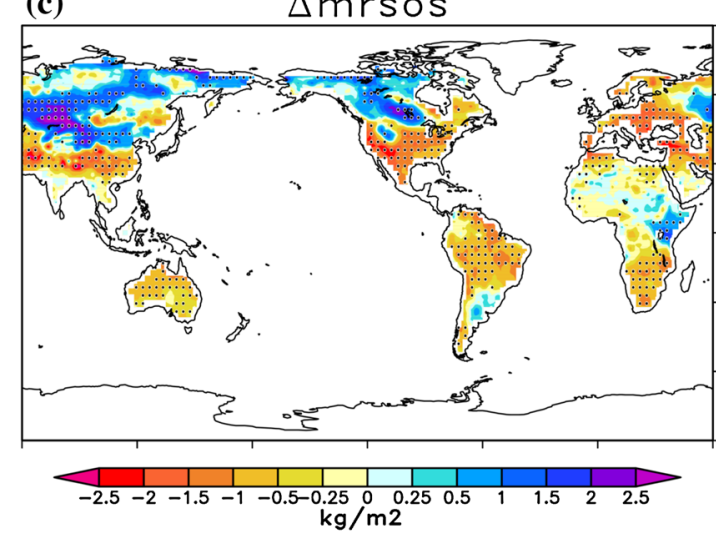

(e)

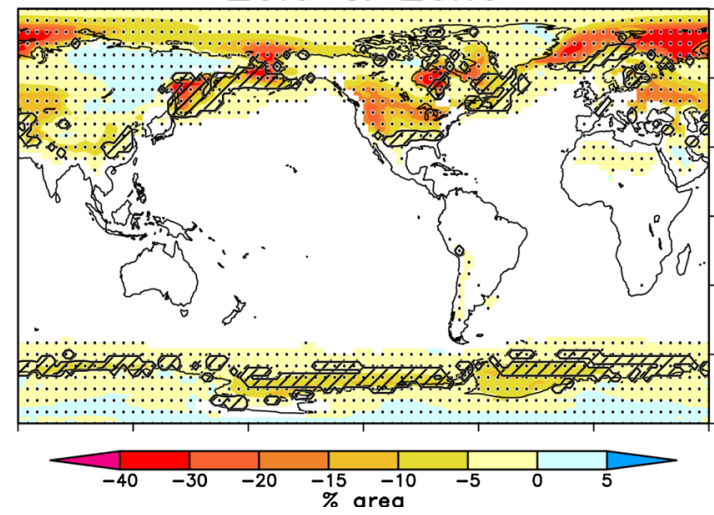

Fig. 5 DJF MME mean changes in a surface wind speed (coloring) and surface wind vectors, $\mathbf{b}$ surface wind divergence (coloring: changes; contours every $2 \times 10^{-6} \mathrm{~s}^{-1}$ : historical run), c surface soil moisture content, $\mathbf{d}$ temperature contrast at the surface $\left(T_{s}^{*}-T_{\text {air }}\right.$, where $T_{s}^{*}$ equals SST over oceans (including sea-ice cover regions) and skin-surface temperature on land), e sea-ice and snow area cover, f surface air (2-m) relative humidity. In a, surface wind vectors are (b) $\nabla \cdot v_{s} \& \quad \Delta \nabla \cdot v_{s}$

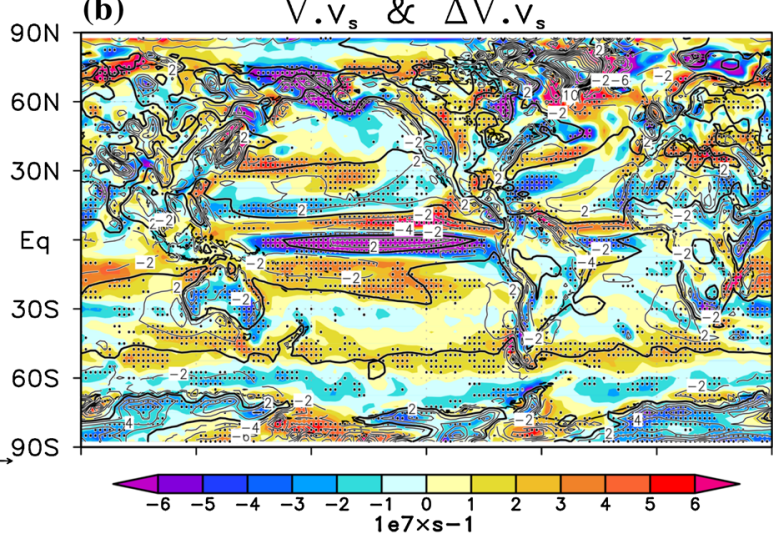

(d) $\Delta \delta T_{\mathrm{s}}^{*}$
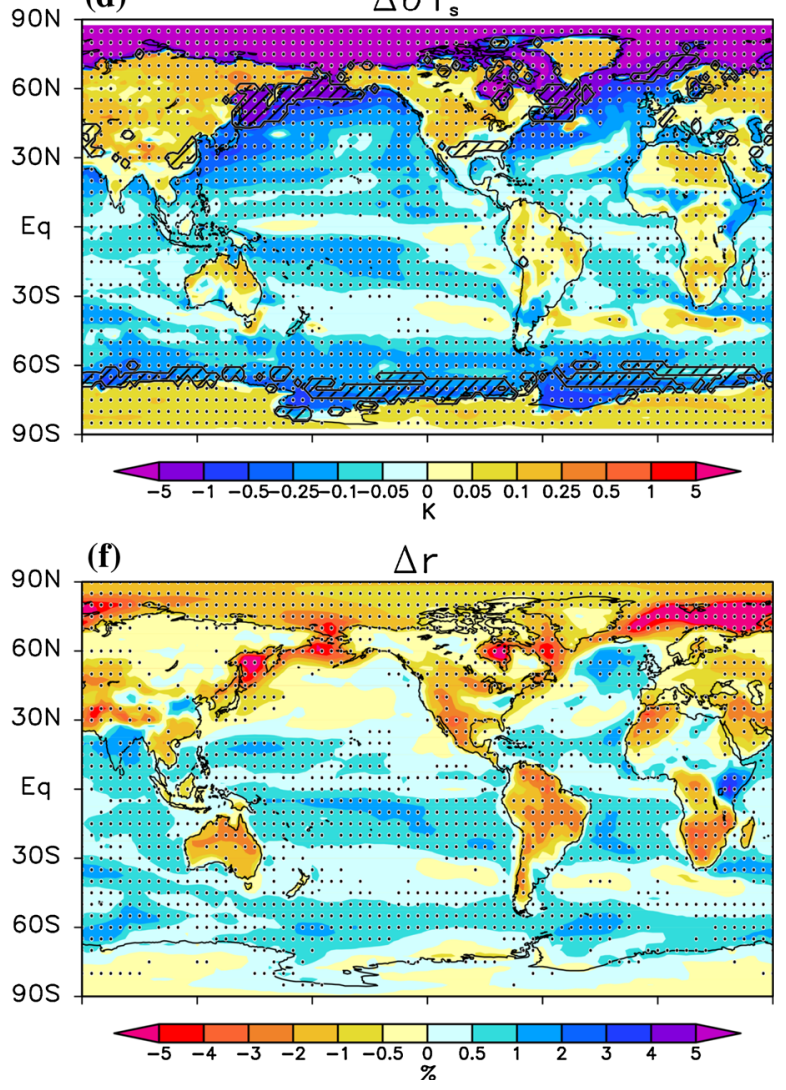

plotted only for regions where the sign of surface wind speed changes are robust among models. Dotted regions indicate those in which the sign of the changes is robust among the models (cf. Sect. 2). Hatched domains in $\mathbf{d}$ and $\mathbf{e}$ represent regions where sea-ice or snow cover has decreased under $5 \%$ of the grid cell considered. The MME mean includes 25 models in $\mathbf{a}, \mathbf{b}, \mathbf{d}, \mathbf{e}$ for sea-ice cover and $\mathbf{f}, 23$ models for c and 13 models for snow cover in e (cf. Table 1) can rewrite the relationship to highlight the effect of surface air relative humidity and thermal contrast $\delta T_{s}^{*}=$ $T_{s}^{*}-T_{\text {air }}$ on the humidity contrast:

$$
\begin{aligned}
\delta q_{s}^{*} & =q_{\mathrm{sat}}\left(T_{s}^{*}\right)-r \times q_{\mathrm{sat}}\left(T_{\mathrm{air}}\right) \\
& =(1-r) \times q_{\mathrm{sat}}\left(T_{s}^{*}\right)+r \times \frac{\partial q_{\mathrm{sat}}}{\partial T}\left(T_{s}^{*}\right) \times \delta T_{s}^{*} .
\end{aligned}
$$


(a)

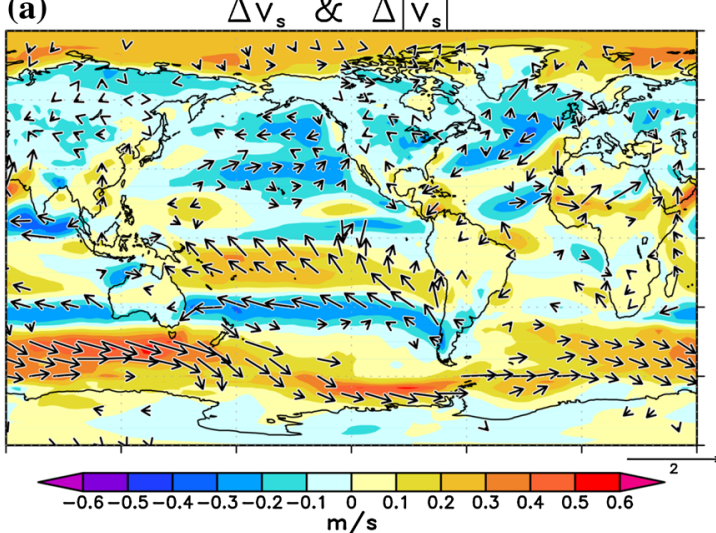

(c)

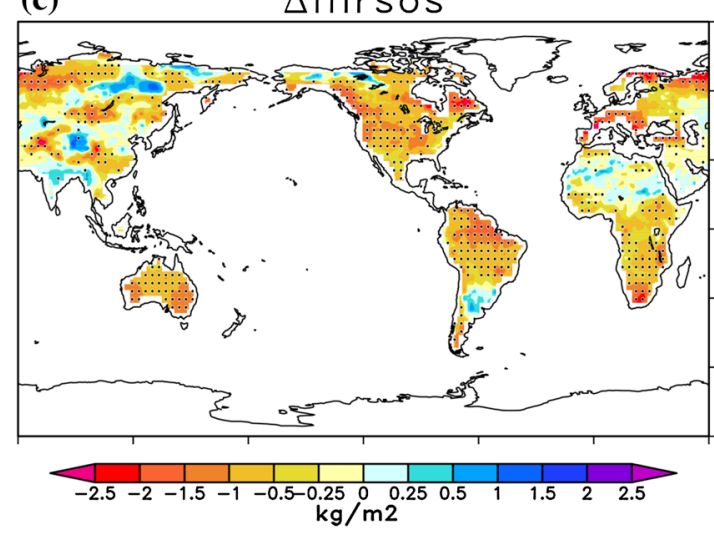

(e)

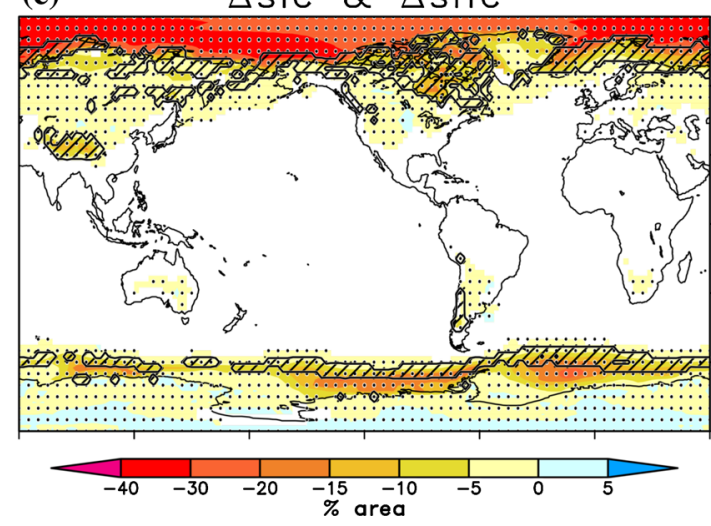

Fig. 6 Same as Fig. 4 but for JJA season

The first term on the RHS represents surface humidity contrast due solely to relative humidity of the air. Even with no air-sea temperature difference $\left(\delta T_{s}^{*}=0\right)$, unsaturated air induces evaporation. The second term represents the contribution from the near-surface thermal contrast. These two contributions are illustrated in Fig. 7 a.

Linearizing (12) for the projected changes in $T_{s}^{*}, \delta T_{s}^{*}$ and $r$, we can write:

\section{$J J A$}

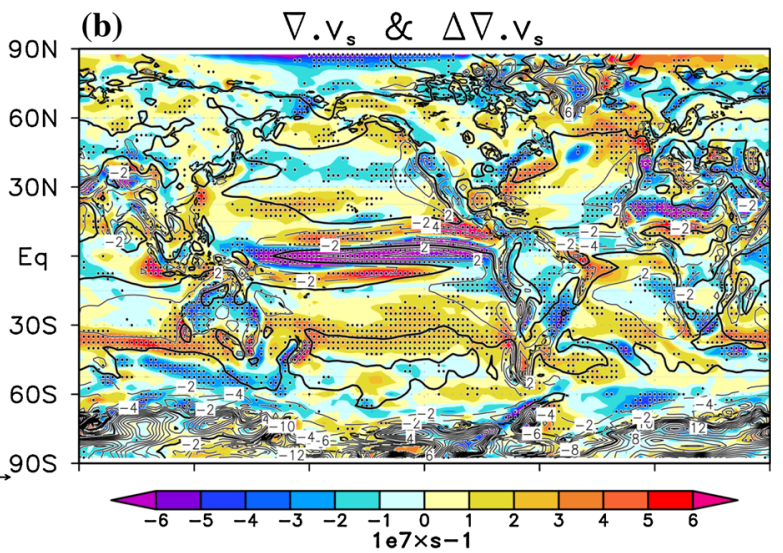

(d) $\quad \Delta \delta T_{\mathrm{s}}^{*}$
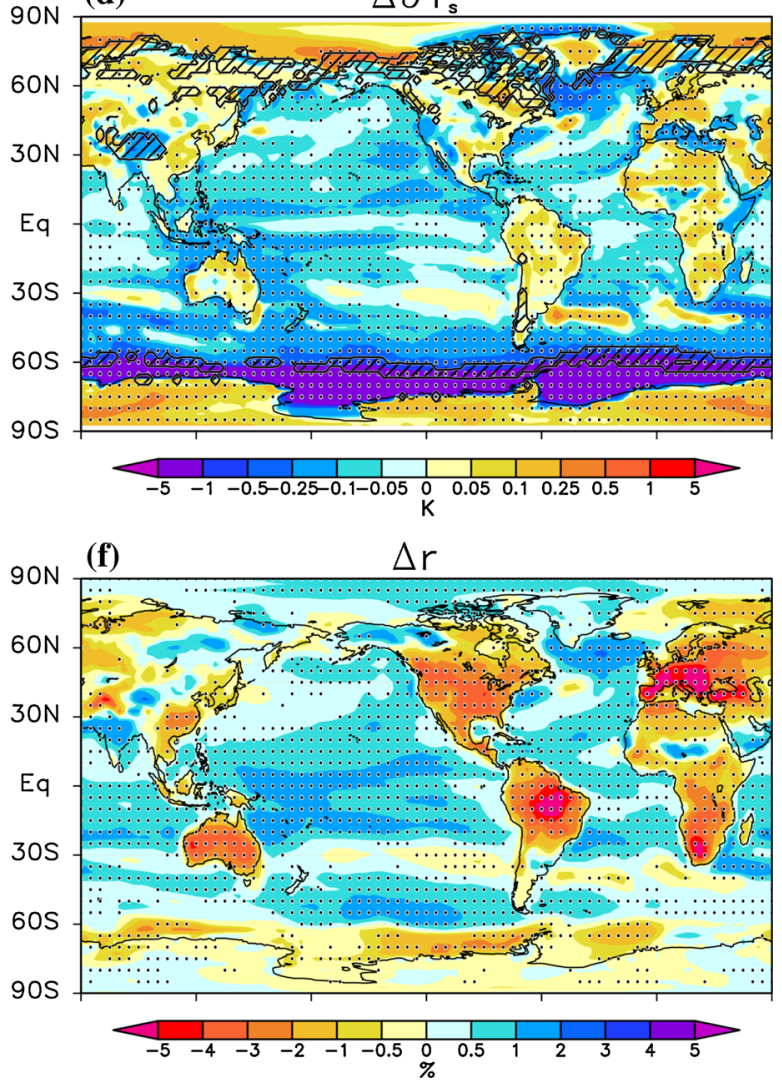

$$
\begin{aligned}
\Delta \delta q_{s}^{*}= & (1-r) \times \frac{\partial q_{\mathrm{sat}}}{\partial T}\left(T_{s}^{*}\right) \times \Delta T_{s}^{*}+r \times \frac{\partial^{2} q_{\mathrm{sat}}}{\partial T^{2}}\left(T_{s}^{*}\right) \times \delta T_{s}^{*} \times \Delta T_{s}^{*} \\
& +r \times \frac{\partial q_{\mathrm{sat}}}{\partial T}\left(T_{s}^{*}\right) \times \Delta \delta T_{s}^{*}-q_{\mathrm{sat}}\left(T_{\mathrm{air}}\right) \times \Delta r+\Delta_{\text {residue }} \delta q_{s}^{*} .
\end{aligned}
$$

As illustrated in Fig. 7c, the first term on the RHS of (13) estimates the contribution from the projected surface temperature change that would be realized without thermal contrast and with no change in surface relative humidity (referred 


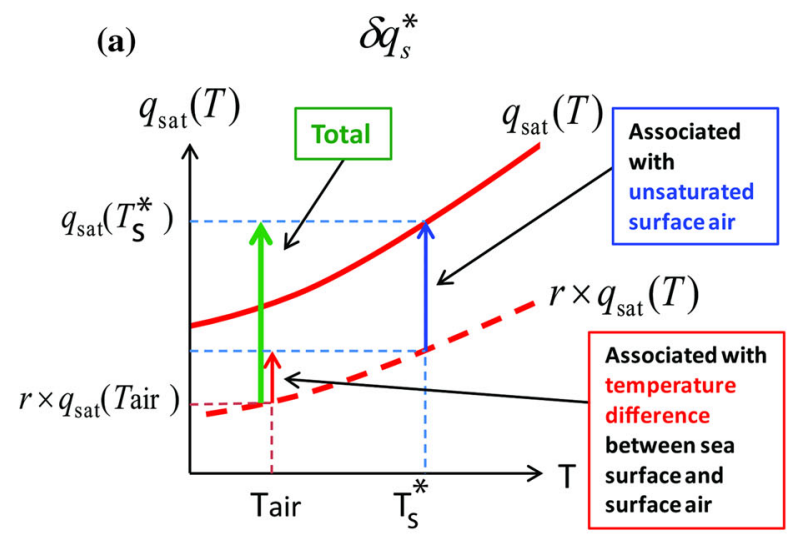

(b)

$\Delta \delta q_{s}^{*}$

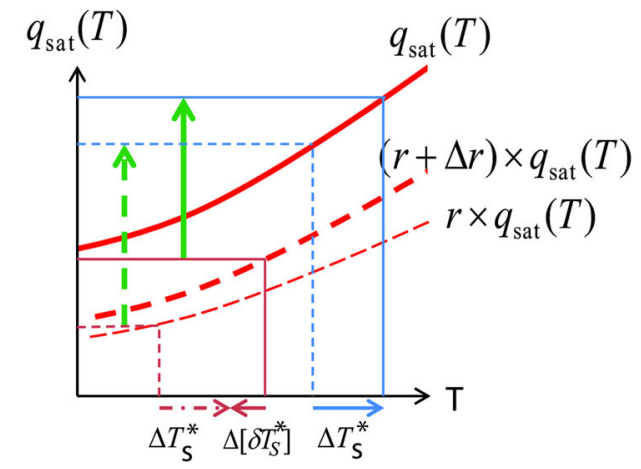

(c)

$\Delta_{\mathrm{T} 1} \delta q_{s}^{*}$

(d)

$$
\Delta_{\mathrm{T} 2} \delta q_{s}^{*}
$$
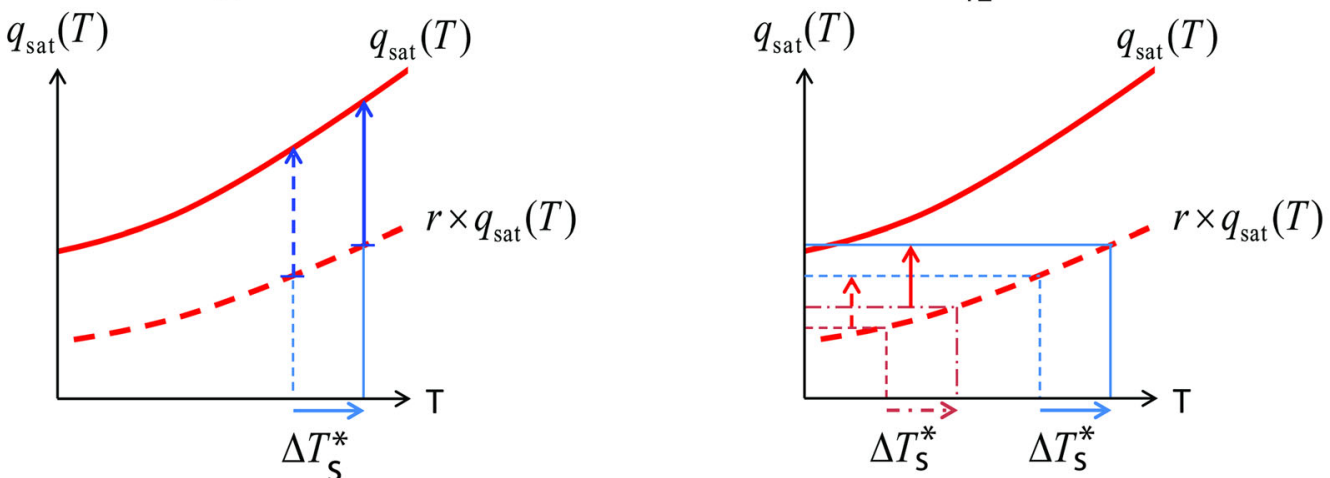

(e)

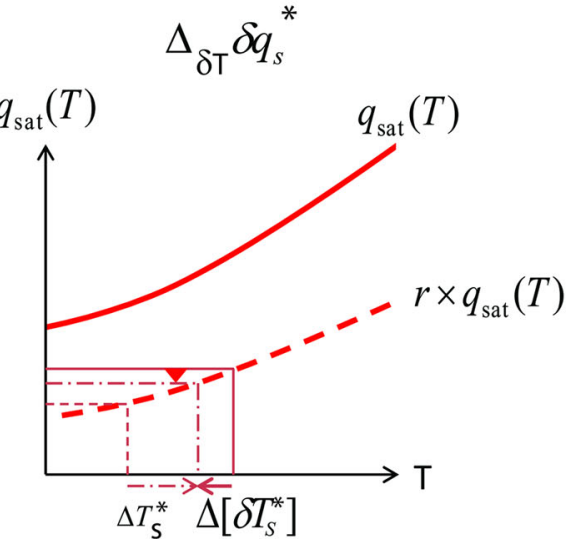

(f)

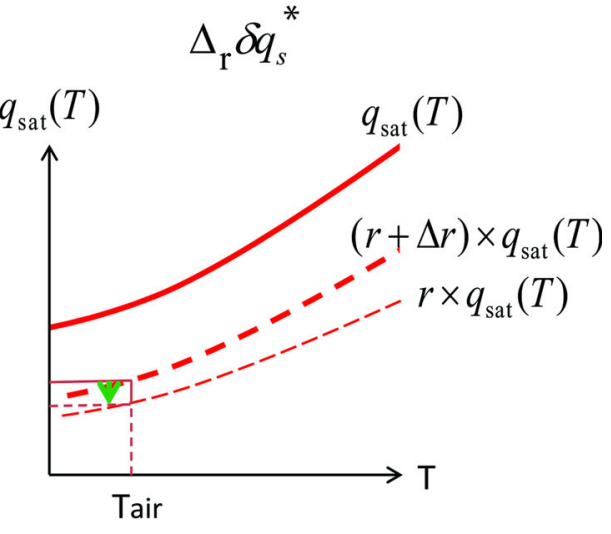

dashed vertical arrows, while in panels $\mathbf{e}-\mathbf{f}$ the contributions are directly indicated as the vertical arrows

(b-f) in Eq. (13). In panels $\mathbf{b}-\mathbf{d}$, contributions of individual terms in the equation are indicated as the differences between the solid and

to as $\Delta_{T 1} \delta q_{s}^{*}$ in Figs. $\left.7,8,9\right)$. Since $\partial q_{\mathrm{sat}} / \partial T \approx \frac{L_{v}}{R_{v} T^{2}} q_{\mathrm{sat}}(T)$ is always positive, the contribution from this term with increasing $T_{s}^{*}$ always acts to enhance the surface humidity contrast. The second term $\left(\Delta_{T 2} \delta q_{s}^{*}\right)$ represents a similar but indirect effect that is of secondary importance via nonlinearity of the Clausius-Clapeyron relationship (Fig. 7d). For a statically unstable situation at the surface with $\delta T_{s}^{*}>0$, surface warming also acts to increase the air-surface humidity

difference, since $\partial^{2} q_{\text {sat }} / \partial T^{2}$ is also always positive. The third term in (13) estimates the contribution from a change in air-sea temperature difference $\delta T_{s}^{*}$ that would be realized under the fixed surface temperature $\left(\Delta_{\delta T} \delta q_{s}^{*}\right.$, Fig. 7e). Specifically, a greater (smaller) increase in $T_{s}^{*}$ than in $T_{\text {air }}$ acts to enhance (reduce) surface evaporation. The fourth term estimates the contribution from a relative humidity change at the surface that would be realized under the fixed $T_{s}^{*}$ and $T_{\text {air }}\left(\Delta_{r} \delta q_{s}^{*}\right.$, 


\section{$D J F$}
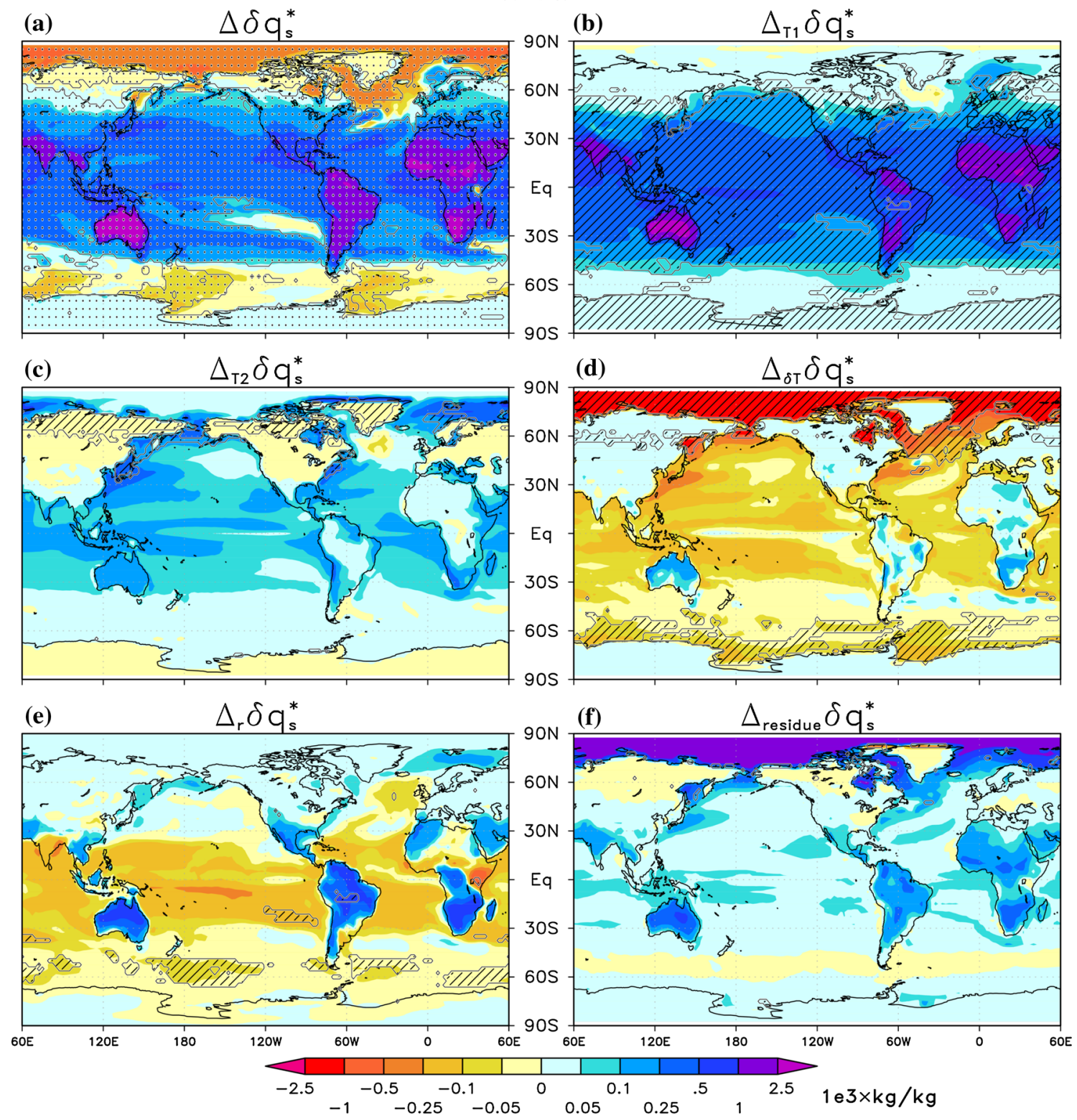

Fig. 8 25-model ensemble mean (cf. Table 1) contributions from individual terms in Eq. (13) for the DJF season. Dotted regions in a indicate those in which the sign of the change is robust among the

models (cf. Sect. 2). Hatched regions in b-f represent those in which a particular contribution dominates the change in $\mathbf{a}$

Fig. 7f), showing that an increase (decrease) in air relative humidity acts to reduce (augment) the specific humidity difference at the surface. Finally, $\Delta_{\text {residue }} \delta q_{s}^{*}$ includes some higher-order contributions, interannual and sub-monthly variability, as we have derived this equation for monthly data. We have also performed the estimation based on daily output from the 6 models listed in Table 1, and we have confirmed that the particular estimation yields only small differences from the results based on the monthly data from the same models. Therefore, as in Sect. 5, we decided to use monthly data instead of daily ones in order to take advantage of the greater number of models available.

Figures 8 and 9 show the 25 -model mean results for DJF and JJA, respectively, based on (13). As dotted in Figs. 8a and $9 \mathrm{a}$, the estimated changes in surface humidity contrast are found to be robust among the 25 models over the global ocean, expect for regions where those changes are small. Contributions from the individual terms of (13) are displayed in Figs. 8b-f and $9 b-f$. In each of these panels, any region is hatched where the contribution from a given term is 
(a)

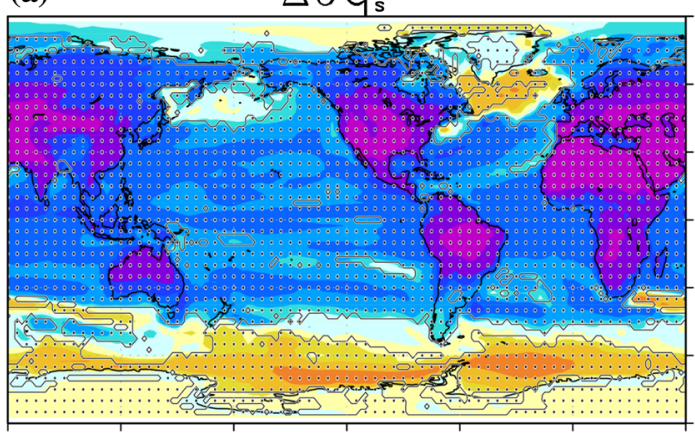

(c)

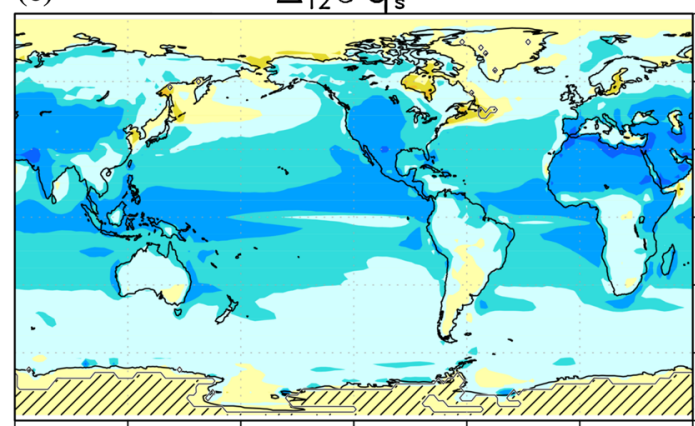

(e) $\quad \Delta_{\mathrm{r}} \delta \mathrm{q}_{\mathrm{s}}^{*}$

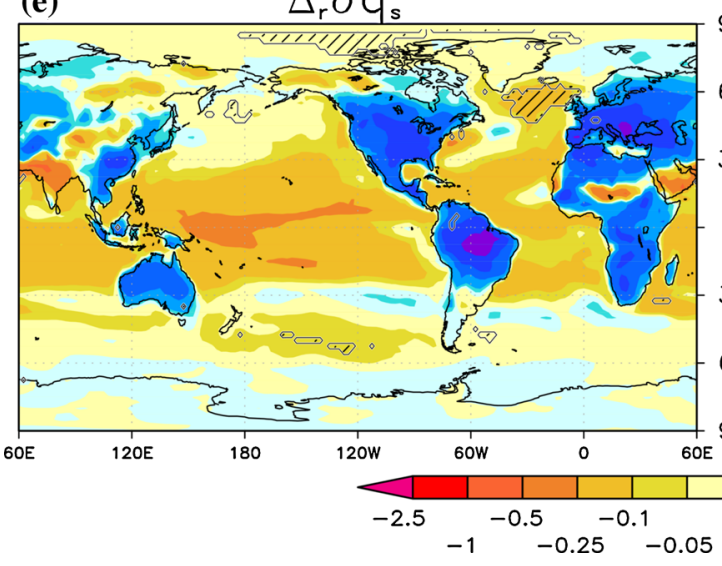

$J J A$

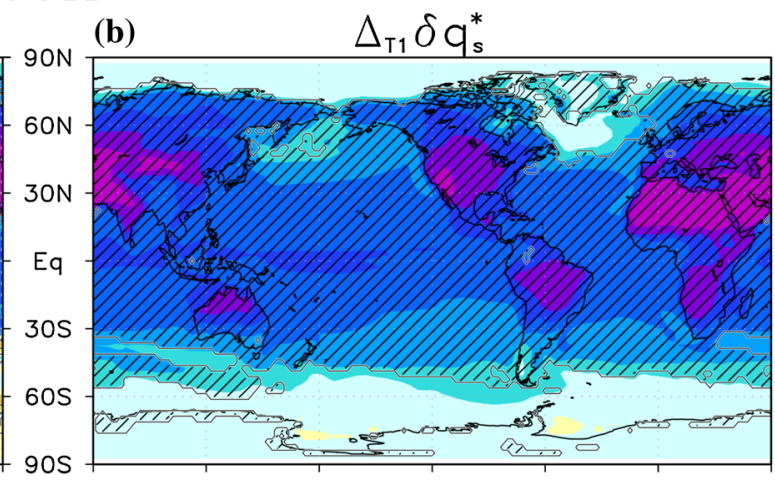

(d)

$\Delta_{\delta \mathrm{T}} \delta \mathrm{q}_{\mathrm{s}}^{*}$

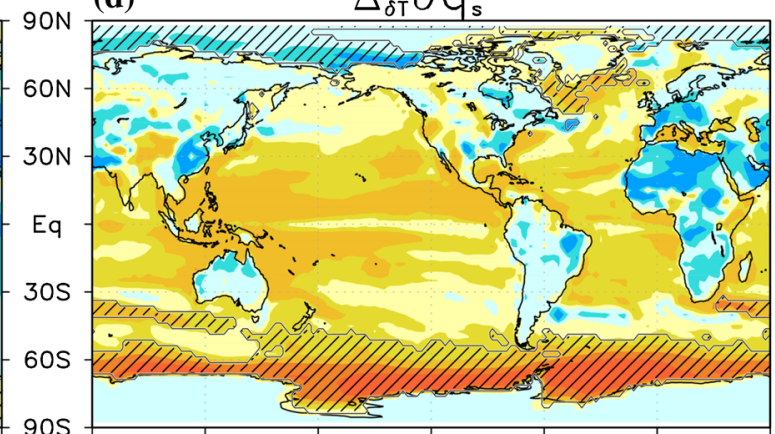

(f) $\quad \Delta_{\text {residue }} \delta \mathrm{q}_{\mathrm{s}}^{*}$

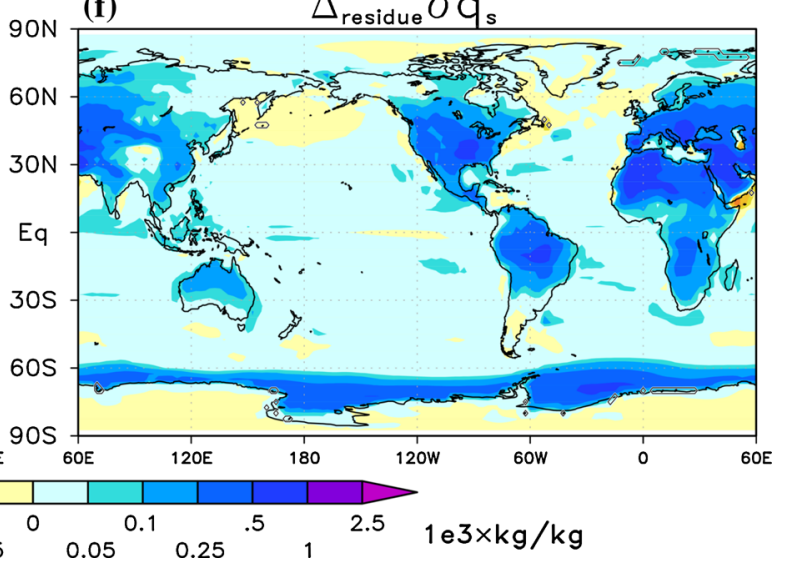

Fig. 9 As in Fig. 6, but for the JJA season

dominant over that from any other term. The overall increase in the surface humidity contrast in the Tropics, subtropics and midlatitudes (roughly between $50^{\circ} \mathrm{S}$ and $50^{\circ} \mathrm{N}$ for both seasons, plus the boreal high latitudes over the continents during JJA) is largely determined by increasing surface temperature under the unsaturated condition (Figs. 8b, 9b). Nonlinearity in the Clausius-Clapeyron relationship under the warmed climate contributes positively, but the contribution is, of course, generally small (Figs. 8c, 9c).

The general tendency of weaker warming of SST relative to $T_{\text {air }}$ warming (Figs. $5 \mathrm{~d}, 6 \mathrm{~d}$ ) acts to reduce evaporation (Figs. 8d, 9d), especially in the subpolar oceans, although the particular tendency can be attributed, at least partly, to the increasing evaporative cooling of the ocean surface (Sutton et al. 2007; Laîné et al. 2009). The thermal contrast changes are also dominantly responsible for the surface specific humidity contrast over the polar oceans, where part of the excessive heat contributes to melting seaice rather than warming the ocean. A future increase in near-surface relative humidity over most parts of the oceans, especially in the subtropics (Figs. 5f, 6f), acts to reduce the air-surface humidity difference and therefore evaporation (Figs. 8e, 9e). In many of the continental regions, drier land surface acts to lower surface air relative 
humidity (Figs. 5c, f, 6c, f), which tends to support enhanced evaporation (Figs. 8e, 9e). This tendency, however tends to be offset by the contribution from the reduction of the exchange coefficient related to less availability of soil moisture (Figs. 3c, 4c). Figures $8 \mathrm{f}$ and 9f indicate the sum of the interactions between the different changes themselves (along with variability changes but of smaller importance, not shown), which indicate that they indeed are weaker than the first-order terms.

\section{Conclusions}

In this study, we have shown that evaporation changes projected in global climate model simulations under the increasing concentration of GHGs is characterized by evaporation enhancement for both DJF and JJA seasons, except over some continental regions and some portions in the subpolar Southern Ocean and North Atlantic. Evaporation changes only explain about $11-16 \%$ of precipitation changes globally but are more important over land, especially in summer (Sect. 3). We have also pointed out that relative changes in evaporation tend to be greater than those in precipitation in subpolar and polar regions but less in the Tropics and subtropics, as a measure of direct effect on the local contribution of evaporation to precipitation (Sect. 4).

The evaporation changes projected for both the DJF and JJA seasons arise largely from changes in air-surface difference in specific humidity (Sect. 5). Exceptions are highlatitude oceans where the effect of sea-ice retreat dominates and some continental areas where changes in the exchange coefficient representing surface soil and vegetation changes among other parameters are important. Though not necessarily negligible, changes in surface wind speed tend to be only of the secondary importance in accounting for the evaporation changes. A noticeable exception is, however, found in the wintertime subtropical South Pacific, where a large increase in surface wind speed results in enhanced evaporation. It should be reminded that the method used in this section should lead to greater discrepancies over land than over the oceans.

The changes in the air-surface humidity difference (Sect. 6) are found to arise mostly from the direct effect of increasing $T_{s}^{*}$ and $T_{\text {air }}$ through enhanced saturation level of near-surface air over extensively regions in the Tropics and midlatitudes and also over subpolar regions. Over most of the oceans, near-surface relative humidity tends to increase in the model projections, which partly offsets the direct warming effect. Over most of the continents, changes in surface air relative humidity do not drive evaporation changes, but rather reflect the changes in surface soil moisture, exerting weak negative feedbacks on evaporation processes. Weaker warming in SST than in $T_{\text {air }}$ also acts to reduce evaporation in these projections. This contribution is only of secondary importance over the Tropical, subtropical and midlatitude oceans, whereas it is the dominant factor over the subpolar oceans.

In conclusion, one of the important results of this study is that, in most regions of both the summer and winter hemispheres, the primary factor for the projected evaporation changes is the warming at the surface and air just above. Held and Soden (2006) have shown that a simple approximate relationship $\Delta[P-E] \approx \frac{L_{v}}{R_{v} T^{2}} \Delta T \times(P-E)$, with lower-tropospheric temperature $T$, can largely explain the first-order, robust response of the hydrological cycle projected in global climate models under increasing GHG concentrations. Following Held and Soden (2006) by considering only the direct thermal effect on evaporation and approximating $T_{\text {air }}=T_{s}$, we can also derive a similar simple relationship from (6) and (7) for evaporation as:

$\Delta E \approx \frac{L_{v}}{R_{v} T_{s}^{2}} \Delta T_{s} \times E$.

Figures $8 \mathrm{~b}-\mathrm{c}, 9 \mathrm{~b}-\mathrm{c}$ approximately represent this warming effect on the projected changes in near-surface humidity contrast and hence evaporation. Apparently, however, this approximation tends to largely overestimate the evaporation changes in the Tropics, subtropics and midlatitudes, where the direct thermal effect in (14) tends to be counteracted by such processes as a reduction in wind speed and thermal contrast at the surface, increasing nearsurface relative humidity over large parts of the oceans and drying of large portions of land surfaces. Furthermore, the approximation is not appropriate over the subpolar and polar regions, where the near-surface thermal contrast and sea-ice changes are more important than the direct thermal effect. Unlike for $P-E$ changes, a simple, useful relationship seems difficult to obtain for evaporation changes.

Acknowledgments We would like to thank the anonymous reviewers for their constructive comments that greatly contributed to simplify and improve the readability of this article. This work is supported in part by the Japanese Ministry of Environment through the Environment Research and Technology Development Fund A1201 and by the Japanese Ministry of Education, Culture, Sports, Science and Technology (MEXT) through a Grant-in-Aid for Scientific Research in Innovative Areas 2205.

Open Access This article is distributed under the terms of the Creative Commons Attribution License which permits any use, distribution, and reproduction in any medium, provided the original author(s) and the source are credited.

\section{References}

Chang EKM, Guo YJ, Xia XM (2012) CMIP5 multimodel ensemble projection of storm track change under global warming. J Geophys Res Atmos 117:D23118 
DiNezio PN, Vecchi GA, Clement AC (2013) Detectability of changes in the walker circulation in response to global warming. J Climate 26:4038-4048

Ducoudré NI, Laval K, Perrier A (1993) SECHIBA, a new set of parameterizations of the hydrologic exchanges at the landatmosphere interface within the LMD atmospheric general circulation model. J Clim 6:248-273

Held IM, Soden BJ (2006) Robust reponses of the hydrological cycle to global warming. J Climate 19:5686-5699

Hu YY, Tao LJ, Liu JP (2013) Poleward expansion of the hadley circulation in CMIP5 simulations. Adv Atmos Sci 30:790-795

Huntington TJ (2006) Evidence for intensification of the global water cycle: review and synthesis. J Hydrol 319:83-95

Jung M et al (2010) Recent decline in the global land evapotranspiration trend due to limited moisture supply. Nature 467:951-954

Koster RD et al (2004) Regions of strong coupling between soil moisture and precipitation. Science 305:1138-1140

Laîné A, Kageyama M, Braconnot P, Alkama R (2009) Impact of greenhouse gas concentration changes on surface energetics in IPSL-CM4: regional warming patterns, land-sea warming ratios, and glacial-interglacial differences. J Climate 22:4621-4635

Liu ML, Tian HQ, Lu CQ, Xu XF, Chen GS, Ren W (2012) Effects of multiple environment stresses on evapotranspiration and runoff over eastern China. J Hydrol 426:39-54

Lu J, Vecchi G, Reichler T (2007) Expansion of the Hadley Cell under global warming. Geophys Res Lett 34:L06805

Miller MJ, Beljaars ACM, Palmer TN (1992) The sensitivity of the ECMWF model to the parametrization of evaporation from the tropical oceans. J. Climate 5:418-434

Mueller B, Seneviratne SI, Jimenez C, Corti T, Hirschi M, Balsamo G, Ciais P, Dirmeyer P, Fisher JB, Guo Z, Jung M, Maignan F, McCabe MF, Reichle R, Reichstein M, Rodell M, Sheffield J, Teuling AJ, Wang K, Wood EF, Zhang Y (2011) Evaluation of global observations-based evapotranspiration datasets and IPCC AR4 simulations. Geophys Res Lett 38:L06402. doi:10.1029/ 2010GL046230

Oki T, Kanae S (2006) Global hydrological cycles and world water resources. Science 313:1068-1072

Peixoto JP, Oort AH (1992) Physics of climate. American Institute of Physics Press, p 520

Seager R, Naik N, Vecchi GA (2010) Thermodynamical and dynamical mechanisms for large-scale changes in the hydrological cycle in response to global warming. J Clim 23:4651-4668

Seneviratne SI, Corti T, Davin EL, Hirschi M, Jaeger EB, Lehner I, Orlowsky B, Teuling AJ (2010) Investigating soil moistureclimate interactions in a changing climate: a review. Earth Sci Rev 99:125-161

Solomon et al. (2007) Climate Change 2007: The physical science basis. Contribution of Working Group I to the Fourth Assessment Report of the Intergovernmental Panel on Climate Change. Cambridge University Press, p 996

Sutton RT, Dong BW, Gregory JM (2007) Land/sea warming ratio in response to climate change: IPCC AR4 model results and comparison with observations. Geophys Res Lett 34:L02701

Takata K, Emori S, Watanabe T (2003) Development of the minimal advanced treatments of surface interaction and runoff. Global Planet Change 38:209-222

Taylor KE, Stouffer RJ, Meehl GA (2012) An overview of CMIP5 and the experiment design. Bull Am Meteorol Soc 93(4):485-498

van der Ent RJ, Savenije HHG (2011) Length and time scales of atmospheric moisture recycling. Atm Chem Phys 11:1853-1863

Vecchi GA, Soden BJ (2007) Global warming and the weakening of the tropical circulation. J. Climate 20:4316-4340 